\title{
Effects of $d$-amphetamine and morphine on behavior maintained by fixed -interval schedules
}

Jennifer L. Johnson

West Virginia University

Follow this and additional works at: https://researchrepository.wvu.edu/etd

\section{Recommended Citation}

Johnson, Jennifer L., "Effects of $d$-amphetamine and morphine on behavior maintained by fixed -interval schedules" (2002). Graduate Theses, Dissertations, and Problem Reports. 1587.

https://researchrepository.wvu.edu/etd/1587

This Dissertation is protected by copyright and/or related rights. It has been brought to you by the The Research Repository @ WVU with permission from the rights-holder(s). You are free to use this Dissertation in any way that is permitted by the copyright and related rights legislation that applies to your use. For other uses you must obtain permission from the rights-holder(s) directly, unless additional rights are indicated by a Creative Commons license in the record and/ or on the work itself. This Dissertation has been accepted for inclusion in WVU Graduate Theses, Dissertations, and Problem Reports collection by an authorized administrator of The Research Repository @ WVU.

For more information, please contact researchrepository@mail.wvu.edu. 


\title{
EFFECTS OF d-AMPHETAMINE AND MORPHINE ON BEHAVIOR MAINTAINED BY FIXED-INTERVAL SCHEDULES
}

\author{
Jennifer L. Johnson
}

Dissertation submitted to the College of Arts and Sciences at West Virginia University

in partial fulfillment of the requirements for the degree of

Doctor of Philosophy

In Psychology

David W. Schaal, Ph.D., Chair Philip N. Chase, Ph.D. Stanley H. Cohen, Ph.D. Kennon A. Lattal, Ph.D. David J. Smith, Ph.D.

Department of Psychology

Morgantown, West Virginia 2002

Keywords: clock stimuli, rate-dependency Copyright 2002 Jennifer L. Johnson 


\section{ABSTRACT \\ EFFECTS OF d-AMPHETAMINE AND MORPHINE ON BEHAVIOR MAINTAINED BY FIXED-INTERVAL SCHEDULES}

\section{Jennifer L. Johnson}

The present experiments tested the effects of d-amphetamine and morphine on pigeons' responding during conventional and clocked FI schedules of food reinforcement. The first experiment compared performance between FI 5-min and continuously clocked FI 5-min components of a multiple schedule in which the rate of the houselight flashing increased in a continuous manner. The second experiment examined the differences between keypecking maintained by FI 5-min, response-dependent clocked FI 5-min, and response-independent clocked FI 5-min components of a multiple schedule. In the response-dependent clocked FI component, each peck produced a stimulus change that was correlated with the passage of time, while the responseindependent clocked FI component provided the stimulus change without a peck requirement. The main effect of both d-amphetamine and morphine was an increase in early-interval responding in all FI components. This result was not consistent with previous studies in that usually behavior under the control of clock stimuli is resistant to the early rate-increasing effects of these drugs. While attending to time in the interval is beneficial in FI schedules, added clock stimuli may remove this importance allowing for drugs to have their effect by causing the pigeons to fail to attend to the relevant stimuli such that other factors control responding. 


\section{Acknowledgements}

My advisor and mentor, Dave Schaal, deserves credit on a number of levels. He provided me with a wonderful balance of independence and guidance with all aspects of my graduate career. His support will never be forgotten. Many thanks to my dissertation committee members Phil Chase, Stan Cohen, Andy Lattal, and Dave Smith for their helpful contributions to this research. I would like to express gratitude to the Schaal lab members Amy Odum, Lori Murray, and Todd Knealing for making suggestions about everything and carrying on meaningful discussions. I am extremely thankful to my undergraduate assistants Greg Groves and Dominic Minardi for their dedication to working with the pigeons and helping with data collection. Lastly, I would like to thank my parents for their understanding when I did not visit on holidays and for their overall support of my educational endeavors. 
Table of Contents

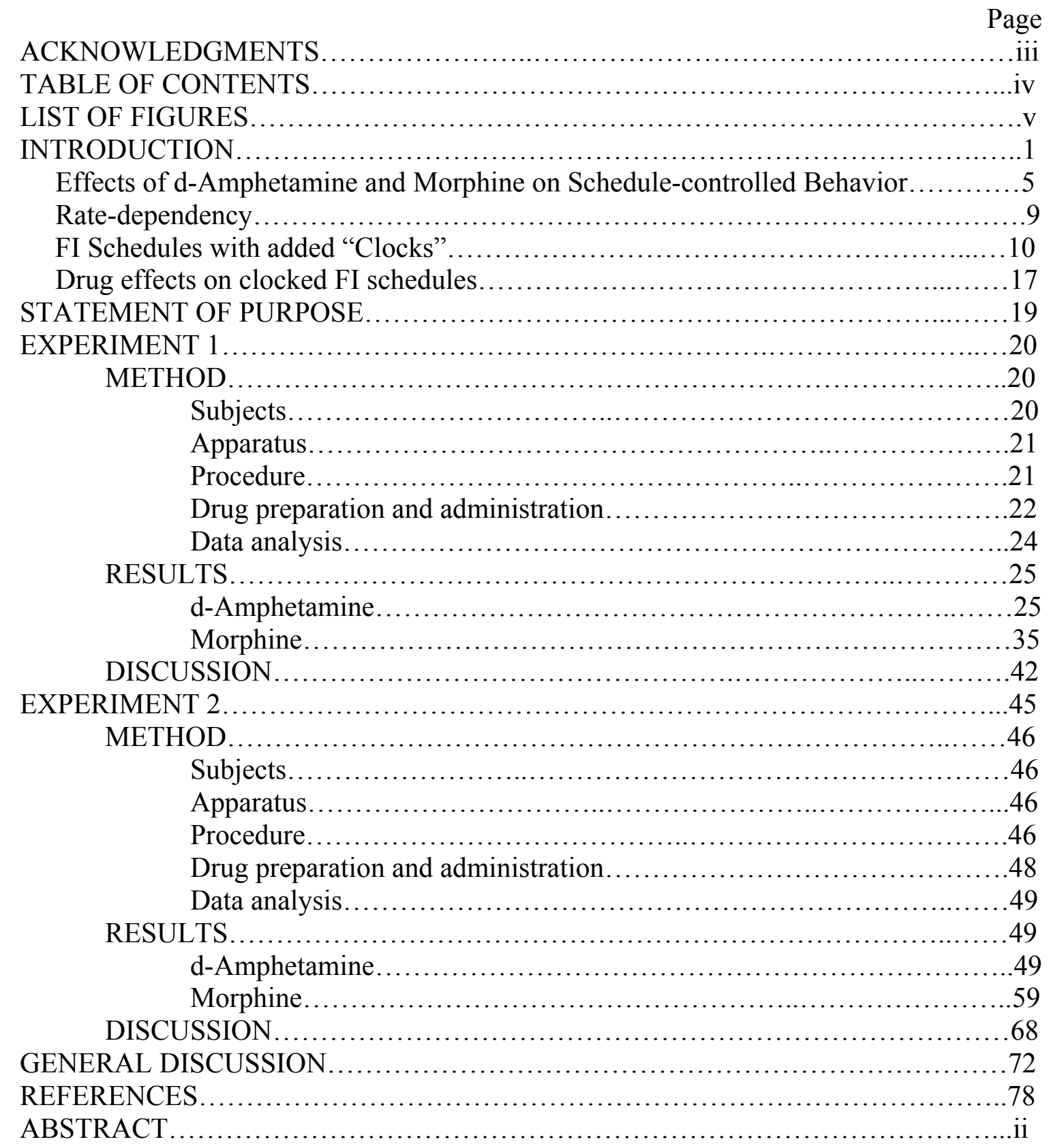




\section{List of Figures}

Figure 1. Duration of houselight stimulus change during the continuously clocked FI 5-

$\min$.

Figure 2. Index of curvature, percent of baseline index of curvature, and rates of key pecking during the FI and clocked FI components as a function of d-amphetamine dose....

Figure 3. Index of curvature and rates of key pecking during the first and last drug determinations during the FI and clocked FI components as a function of d-amphetamine dose

Figure 4. Total key pecks in tenths of the interval during the FI and clocked FI components for d-amphetamine dose.

Figure 5. Index of curvature, percent of baseline index of curvature, and rates of key pecking during the FI and clocked FI components as a function of morphine dose.

Figure 6. Index of curvature and rates of key pecking during the first and last drug determinations during the FI and clocked FI components as a function of morphine dose.

Figure 7. Total key pecks in tenths of the interval during the FI and clocked FI components for morphine dose.

Figure 8. Index of curvature, percent of baseline index of curvature, and rates of key pecking during the FI, response-dependent clocked FI, and response-independent clocked FI components as a function of d-amphetamine dose....

Figure 9. Index of curvature and rates of key pecking during the first and last drug determinations during the FI, response-dependent clocked FI, and response-independent clocked FI components as a function of d-amphetamine dose....

Figure 10. Rates of key pecking during thirds of the interval during the FI, responsedependent clocked FI, and response-independent clocked FI components as a function of d-amphetamine dose for P597.

Figure 11. Rates of key pecking during thirds of the interval during the FI, responsedependent clocked FI, and response-independent clocked FI components as a function of d-amphetamine dose for P425

Figure 12. Rates of key pecking during thirds of the interval during the FI, responsedependent clocked FI, and response-independent clocked FI components as a function of d-amphetamine dose for P829... 
Figure 13. Rates of key pecking during thirds of the interval during the FI, responsedependent clocked FI, and response-independent clocked FI components as a function of d-amphetamine dose for Pa30

Figure 14. Index of curvature, percent of baseline index of curvature, and rates of key pecking during the FI, response-dependent clocked FI, and response-independent clocked FI components as a function of morphine dose.

Figure 15. Index of curvature and rates of key pecking during the first and last drug determinations during the FI, response-dependent clocked FI, and response-independent clocked FI components as a function of morphine dose.

Figure 16. Rates of key pecking during thirds of the interval during the FI, responsedependent clocked FI, and response-independent clocked FI components as a function of

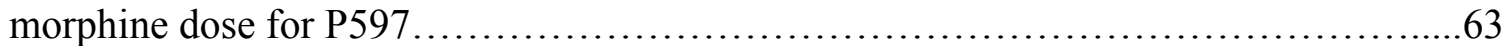

Figure 17. Rates of key pecking during thirds of the interval during the FI, responsedependent clocked FI, and response-independent clocked FI components as a function of morphine dose for P425.

Figure 18. Rates of key pecking during thirds of the interval during the FI, responsedependent clocked FI, and response-independent clocked FI components as a function of

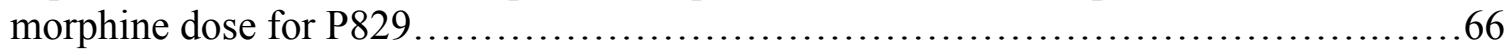

Figure 19. Rates of key pecking during thirds of the interval during the FI, responsedependent clocked FI, and response-independent clocked FI components as a function of morphine dose for Pa30. 
Fixed-interval (FI) schedules of reinforcement arrange for the first operant response after a fixed period of time to be reinforced. For example, on an FI 5-min schedule, five minutes must elapse before a response produces a reinforcer. FI schedules typically produce stable behavior patterns in pigeons that are characterized by a period of no responding at the start of an interval followed by a gradual or abrupt increase in response rates as the next reinforcer approaches (Ferster \& Skinner, 1957). This pattern of behavior, often called the "FI scallop," is highly sensitive to alteration by drugs. Many drugs, including d-amphetamine and morphine (Cook \& Kelleher, 1962; Dews, 1958; Kelleher \& Morse, 1968; Odum, Haworth, \& Schaal, 1998), increase low baseline response rates early in the interval while decreasing or not altering high baseline rates occurring later in the interval. This effect is referred to as the "rate-dependency effect" (Dews, 1958; Dews \& Wenger, 1977). Odum, Haworth, and Schaal (1998) and Schaal, Miller, and Odum (1995) obtained this rate-dependent effect with $3.0 \mathrm{mg} / \mathrm{kg}$ cocaine and $3.0 \mathrm{mg} / \mathrm{kg}$ morphine. The data were presented by plotting response rates of a single pigeon in successive tenths of an FI 5-min schedule under baseline conditions and after administration of the drugs. Early in the interval, rates of pecking increased, but later in the interval the rates were either suppressed or were unaffected. They also found that the rate-increasing effect of these drugs was enhanced when the animals were more severely food deprived (70\% of free-feeding weight vs. 85-90\% of free-feeding weight).

It is safe to say that, of the hundreds of studies in behavioral pharmacology that have employed FI schedules, most of them have done so simply because FI schedules generate a reliable pattern of behavior that is sensitive to drug effects (Branch \& Gollub, 
1974; \& McAuley \& Leslie, 1986). Relatively few studies have sought to determine the behavioral mechanisms of drug-induced alterations in FI-schedule performance (Branch, 1984; Branch \& Schaal, 1990; Thompson \& Schuster, 1968). Thompson (1984) defines "behavioral mechanism of drug action" as a description of a drug's effects on a particular behavior expressed in terms of more general principles of behavior. This statement implies that drugs alter behavior by altering the influence of behavioral variables. The behavioral variables that may serve as behavioral mechanisms are antecedent variables (e.g., deprivation level), current stimulus variables (e.g. stimulus disparity, sensory modality, intensity), historical variables (e.g. drug history, reinforcement variables, prior experience with conditioned reinforcers), and response variables (e.g. response force, location, duration). A behavioral-mechanisms approach would suggest that changes in any of these variables may drastically alter the behavioral effects of drugs, or in other words, drugs have their effects on behavior by altering the function of one or more of these variables. The broad purpose of the present experiments is to address the issue of how drugs alter the behavioral processes that control FI-schedule performance to produce the changes in performance that are typically observed.

More specifically, the experiments examined the effects of variations on a method that has previously been employed in the search for the causes of drug-induced changes in FI schedule performance. This method includes using stimuli that are correlated with the passage of time and is based on the hypothesis that FI schedules produce their characteristic behavior pattern in part because animals discriminate the passage of time since the start of the interval (or they discriminate transitions between behavior states as 
time passes; Killeen \& Fetterman, 1988), and respond based on that discrimination. This view was expressed by Ferster and Skinner (1957):

To the extent that the bird's behavior is an event varying in time and correlated consistently with the FI schedule, it can be thought of as a clock by which the bird may modify its behavior with respect to reinforcement. The terminal rate at the end of the fixed interval represents the most optimal setting of the clock, and the curvature [i.e., the transition from low to high rates] represents intermediate clock settings. With a perfect clock an interval should contain only a single response. The bird's own behavior, however, is a relatively poor clock. (p. 266)

Ferster and Skinner used a procedure similar to that employed in Experiment 1 of the present dissertation to show that, when an external stimulus is correlated with the passage of time in the FI, the pattern of responding changes to one in which much longer pauses are followed by abrupt transitions to high response rates near in time to food reinforcement. It may be asserted that, when these external "clock stimuli" supplement the pigeon's own discrimination of passing time, the temporal pattern of behavior more closely resembles what would be expected if the pigeon were a "perfect clock."

Laties and Weiss (1966) were interested in whether drugs altered this temporal discrimination when clock stimuli were added to an FI schedule. Using pigeons as subjects, Laties and Weiss (1966) and Odum and Schaal (1999) showed that the typical, rate-dependent changes in the pattern of FI-schedule responding produced by several drugs (e.g., pentobarbitol, d-amphetamine, morphine) did not occur when discrete changes in keylight stimuli (referred to here as a "discrete clock") were correlated with the passage of time through the interval. One interpretation of this finding is that these drugs disrupt (specifically, "speed up") the discrimination of time, so that pigeons respond early in the interval under drug. This result does not occur when clock stimuli are added because clock stimuli supplement the pigeon's own discrimination of time, 
making early-interval responding resistant to the rate-increasing effects of the drugs. Clock stimuli provide the animal with a clear signal of time in the interval, which supplement the weak stimulus control maintained by other signals that occur with the passage of time. In other words, the weak stimulus control produced by the passing of time is enhanced by the presentation of time-correlated stimuli, and the strengthened stimulus control is not easily disrupted by drugs. Another interpretation, however, is that the clock stimuli change the task fundamentally, making "timing" unnecessary, such that the signals that are correlated with the passage of time are no longer important signals of time passage. Drugs do not increase response rates during the early clock stimuli because these stimuli are always correlated with the absence of reinforcement. No temporal discrimination is required, according to this notion, until the last clock stimulus (the one that is present when pecking is reinforced) is presented.

The present experiments were designed to help decide between these different interpretations of the "FI-clock effect." They addressed this issue by arranging for stimuli to be correlated with the passage of time but without entirely eliminating control by the passage of time. Experiment 1 accomplished part of this goal by arranging for each clock stimulus (houselight on and houselight off) to be paired with the presentation of food. During the clocked FI component, the keylight was lit blue and the houselight flashed on and off. The rate of flashing increased continuously as the interval elapsed. This procedure made moment-to-moment temporal discriminations more difficult than a discrete clock would. Experiment 2 accomplished this goal by arranging for the clock stimuli to be response-dependent, meaning that a response was required in order to obtain the clock stimuli at any given point in the interval. Finding that drugs alter behavior 
maintained by these procedures as they alter behavior maintained by ordinary FI schedules would support a claim that discrete clocks do not merely supplement the temporal discrimination, but make temporal discrimination unnecessary. When some level of temporal discrimination is required, behavior is sensitive to alteration in a manner similar to conventional FI schedules.

The following literature review will focus mainly on FI schedules and the manner in which previous researchers have viewed the roles of clock stimuli superimposed on FI schedules, in particular as they relate to drug-induced behavior changes. The general effects of the two drugs used in these experiments, morphine and d-amphetamine, will be reviewed also. Finally, the Statement of Purpose will relate the previous studies by Laties and Weiss (1966) and Odum and Schaal (1999) to the variations on FI-clock schedules employed here.

Effects of d-Amphetamine and Morphine on Schedule-controlled Behavior

d-Amphetamine and morphine were chosen for the present experiments in order to compare the present results with key studies involving clocked FI schedules such as Laties and Weiss (1966) who studied the effects of d-amphetamine and Odum and Schaal (1999), who studied the effects of morphine. If temporal discrimination plays a role in controlling performance under FI schedules then the effects of d-amphetamine, a stimulant, and morphine, an opiod analgesic, should be similar even though they come from two different drug classes.

d-Amphetamine is metabolized by the liver and has a half-life of 10-30 hours (Doweiko, 1990). Its effects on the central nervous system (CNS) follow from a release of biogenic amines, particularly norepinephrine, dopamine, and 5-hydroxytryptamine 
(Goodman \& Gilman, 1996). These neurotransmitters stimulate the CNS producing vasoconstriction, hypertension, tremor, an increase in motor activity, and insomnia. The effects of d-amphetamine on behavior maintained by positive reinforcement have been shown in various studies to be rate-dependent (Branch \& Gollub, 1974; Dews, 1958; Leander \& McMillan, 1974; McMillan, 1969). There are several ways to assess ratedependent effects, one of which is to examine the differential effects on high-rate behavior maintained on FR schedules and low-rate behavior maintained by FI schedules. Rate-dependent effects are said to occur if the drug decreases rates of behavior maintained by the FR schedule and increases rates of behavior maintained by the FI schedules. McMillan (1969) examined the effects of d-amphetamine on the key pecking of pigeons on a multiple FR 30 FI 5-min schedule, where the FR 30 schedule generated a response rate of 3.0 responses per second and the FI 5-min schedule generated a response rate of 0.6 responses per second under baseline conditions. d-Amphetamine produced a dose-dependent decrease in responding under the FR component, and an inverted-U shaped function under the FI component. So at some doses, the high rates produced by the FR schedule were decreased, while the lower response rates produced by the FI schedule were increased. Similar results have been found by Katz (1982) and Leander and McMillan (1974).

The most common way to assess the rate-dependent effect of drugs, however, is to examine the effects of a drug on the different baseline rates of behavior generated within a fixed interval. For example, Dews (1958) trained pigeons to peck keys on an FI 15-min schedule of food reinforcement. Administration of d-amphetamine increased the pecking early in the interval while not affecting the behavior occurring later in the 
schedule. Similar results have been obtained by Barrett (1974), McMillan and Healey (1976), McMillan (1979), McAuley and Leslie (1986), Bordi and Matthews (1990) and Cohen (1991).

Branch and Gollub (1974) also studied the effects of d-amphetamine on patterns of pigeons' responding on FI schedules $(300 \mathrm{~s}, 100 \mathrm{~s}$, or $40 \mathrm{~s})$ of food reinforcement. Although intermediate doses increased overall rates for some pigeons, overall rates were either decreased or not affected for other pigeons. A more local analysis revealed more reliable across-subject effects. Under baseline, pigeons pecked at two distinct rates; zero (in the early part of the interval) and high (later in the interval). Variation from interval to interval in the point of transition between these two rates (or two "states"; Schneider, 1969, Baron \& Leinenweber, 1994) resulted in the typical scalloped pattern when rates were averaged over several intervals. A second-by-second record of responding revealed that d-amphetamine decreased the duration of pauses early in the interval and produced intermediate response rates throughout the interval.

A few experiments have examined the effects of d-amphetamine effects on temporal discrimination in animals, and have found that the drug can indeed alter timing (Antoniou \& Kafetzopoulos, 1991; Church, 1984; Geyer, Russo, Segal, \& Kuczenski, 1982; Kraemer, Randall, Dose, \& Brown, 1997; Spetch \& Treit, 1984). Using the peak procedure, Kraemer, et al. (1997) tested the effects of d-amphetamine on pigeons' keypecking. Three pigeons were trained to peck a key on an FI 30 s schedule. A session consisted of 48 trials of the FI 30 s, separated with variable intertrial intervals with a mean of $90 \mathrm{~s}$. This variable intertrial interval allowed for longer probe trials. On test days, 6 of the 48 trials were probes of a longer duration (90 s) and reinforcement was 
withheld. The peak rate of responding occurred at $30 \mathrm{~s}$ during these probe trials, that is, as the time when the bird would normally receive a reinforcer. A dose of $2.0 \mathrm{mg} / \mathrm{kg} \mathrm{d}$ amphetamine produced a leftward shift in the peak compared to saline, indicating that the pigeons start and stop responding earlier as if more time has passed than actually has, thus supporting the claim that alterations in FI-schedule performance reflect a druginduced change in temporal discrimination.

Morphine, a high-efficacy mu-opiod, is metabolized by the liver, and has a halflife of 2-4 hours. One of its metabolites is morphine-6-glucuronide, which mediates most of the analgesic action with chronic administration. It is typically used for treatment of severe pain. It also produces respiratory depression, pupillary constriction, euphoria, and constipation, and is a drug of abuse (Goodman \& Gilman, 1996; Julian, 1998). Ratedependency also describes the effects of morphine on behavior maintained by positive reinforcement in various studies with monkeys (Katz \& Goldberg, 1986; McKearney, 1974), rats (Rhodus, Elsmore, \& Manning, 1974), and pigeons (Heifetz \& McMillan, 1971; Katz \& Goldberg, 1986). For example, Odum, Haworth, and Schaal (1998) found rate-dependent effects of morphine on behavior maintained by a multiple fixed-ratio (FR 30) FI 5-min schedule. They revealed the rate-dependent effects on performance in the FI schedule first by collecting pecks in successive tenths of the interval in separate "bins". The effects of each drug dose on the different rates obtained during the interval were then expressed by plotting the percentage change in response rates from non-drug "control" sessions against the non-drug, control rates. The low rates of keypecking generated in the beginning of the intervals were increased, while the higher rates of keypecking at the end of the intervals decreased. In addition, the FR 30 schedule 
generated rates that ranged from approximately 100 to 300 pecks per minute, while the FI 5-min schedule generated rates in the range of 20 to 70 pecks per minute. Low to moderate doses of morphine decreased the higher rates maintained by the FR schedule and increased the lower rates maintained by the FI schedule. Thus, these results can be described as rate-dependent. The two different methods of graphically representing the data allowed identical conclusions regarding these drugs' rate-dependent effects. As McKearney (1981) points out, no one method is superior mathematically and which method is chosen to present the data is usually a matter of personal choice.

\section{$\underline{\text { Rate-dependency }}$}

Because the effects of d-amphetamine and morphine on behavior maintained by schedules of reinforcement largely depend on the baseline rate of behavior, a note about the concept of rate-dependency is warranted. Although rate-dependency is ubiquitous in behavioral pharmacology, it has some limitations. One is that it suggests that the only important variable is response rate and that behavioral variables are important only to the extent that they produce a given rate (Branch, 1984). Such a view leads one away from analyzing drug effects in terms of behavioral mechanisms such as stimulus control, reinforcement history, etc. Also, there are several drugs (naloxone, physostigmine, quipazine, some tranquilizers) whose effects do not depend upon the baseline rate of behavior; such findings lessened the all-important role of the baseline response rate (Harris, Snell, \& Loh, 1978a; Vaillant, 1967). Further, in one study, the effects of morphine were found to depend on the consequence rather than rate (e.g., McKearney, 1974). In this study, monkeys responded on an FI 5-min schedule of shock presentation and an FI 5-min schedule of food presentation. Both schedules produced comparable 
rates and patterns of responding. Morphine increased the rate of responding when shock was the consequence and decreased the rate of responding when food was the consequence. Another limitation, related to the present study, is that rate-dependent effects are not typically seen when there is strong stimulus control over low response rates (Laties \& Weiss, 1966). These exceptions make it necessary to know more than the baseline rate of behavior in order to predict the effects of a drug on behavior (Robbins, 1981; Sanger \& Blackman, 1974; Branch, 1984).

In spite of these limitations, rate-dependency is still an important issue. Although there are exceptions, it is a widespread phenomenon and any understanding of drug effects on FI-schedule performance must be aware of the role rate-dependency may play in the results. Rate-dependency may also play a role in the present experiments. Adding clock stimuli to FI schedules changes the pattern of behavior from that generated under FI schedules without clock stimuli. Typically when such stimuli are added, response rates early in the interval are lower and sometimes response rates later in the interval are higher than response rates under regular FI schedules. Since there are rate changes that occur along with the addition of stimuli correlated with the passage of time, issues related to rate-dependency must be addressed.

\section{$\underline{\text { FI Schedules with added "Clocks" }}$}

One of the earliest studies concerning control over FI performance by added timecorrelated stimuli was that of Segal (1962), who associated distinct stimuli and abrupt transitions between stimuli with portions of the FI (by using a discrete clock). She tested FI values of $12 \mathrm{~s}, 1 \mathrm{~min}$, and $5 \mathrm{~min}$. In some conditions the clock was responseindependent, meaning that as time passed in the interval the color of the key changed 
independent of the subject's behavior. In other conditions, the clock was responsedependent, meaning that the key was dark unless a peck occurred. A peck produced a stimulus change, which was correlated with the passage of time. For example, the interval was divided into four equal components each with a distinct stimulus $(1=$ red, 2 $=$ green, 3 = white, $4=$ blue). If the pigeon pecked during the $1^{\text {st }}$ fourth of the interval, the key would be lit red for a few seconds, if it pecked during the $2^{\text {nd }}$ fourth of the interval, the key would be lit green for a few seconds, and so forth. The behavior generated by the clocked FI schedule was compared to behavior generated by FI schedules with no clock. In conditions with response-independent clock stimuli, almost all of the keypecking occurred during the last stimulus presentation before food, except for the FI 12-s, where most of the responding occurred during the last 2 stimulus presentations. The behavior patterns in the conditions with response-dependent clock stimuli were similar across the clocked FI and the FI schedules. Both schedules generated a scalloped pattern, but there was more responding during the last quarter of the interval during the clocked FI. The behavior generated under the conditions with response-dependent clock stimuli was intermediate between the conventional FI and the FI with response-independent clock stimuli. Specifically, the response-independent stimuli produced sharper scallops or longer pauses followed by increasing rates of responding, while the conventional FI produced a shorter pause followed by a slower acceleration of responding. The FI schedule with response-dependent stimuli produced behavior that was characterized by a slightly shorter pause than that produced by the response-independent stimuli but longer than that produced by the interval with only one stimulus. The rate of responding increased more abruptly than under the conventional FI 
but slower than rates produced by the response-independent stimuli. This intermediate performance under the response-dependent FI schedule suggests that the pigeons were "timing," or discriminating durations, during more of the interval than under the discrete clocked FI schedule.

Segal suggested that the suppression of responding in the early part of the clocked interval was due to the S- function (an S- is a stimulus correlated with the absence of reinforcement) of the early stimuli in the clock sequence and the higher responding later in the interval was due to the $\mathrm{S}+$ function of the last stimulus in the sequence. In other words, the stimuli associated with the earlier parts of the interval (the first 3 discrete stimuli) were aversive stimuli or punishers and the last stimulus (the fourth discrete stimulus) was a conditioned reinforcer. Kendall (1972) replicated Segal (1962) and addressed further the question of the function of the early stimuli in the clock sequence of an FI schedule. Kendall arranged an FI 2-min schedule with 6 response-dependent clock stimuli. The results replicated Segal's findings (less responding in the presence of all stimuli but the final one). He also found that the post-reinforcement pause (PRP) was longer during the clocked FI than during the conventional FI, suggesting that the early stimuli were indeed conditioned punishers and not conditioned reinforcers.

If early clock stimuli are aversive, then responding on a key that only produces stimuli correlated with the early parts of an FI should not occur frequently. Hendry and Dillow (1966) arranged an FI 6-min schedule on one key and three response-dependent clock stimuli on another key. The clock stimuli only served as observing stimuli produced by responses on that key. That is, the stimuli only appeared for $0.5 \mathrm{~s}$ if the pigeon pecked the observing key; food was not delivered as a consequence for pecking 
the key that produced the clock stimuli. They hypothesized that if the clock stimuli were reinforcing, then the stimuli would function as conditioned reinforcers and not as conditioned punishers. They found that the pigeons did respond on the key that produced the clock stimuli. Specifically, the rate of pecking the observing key increased throughout the interval until the last minute in which the rate dropped due to an increased response rate on the food key. Since the only consequence for pecking the observing key was a production of a stimulus, which roughly indicated the time in the interval, they concluded that all of the clock stimuli were functioning as conditioned reinforcers. The fact that the rate of responding increased as the interval (and, hence, the stimuli) progressed suggests that the stimuli have different "values." Stimuli correlated with the early part of the interval maintained less pecking than stimuli correlated with the later part of the interval. Whether the early-interval stimuli were aversive relative to laterinterval stimuli was not specifically tested.

Auge (1977) stated that "clock control" was characterized by no responding early in the interval followed by all responding later in the interval or that early clock stimuli serve as S- while late clock stimuli serve as S+. Even though Segal (1962) and Kendall (1972) suggested that response-dependent stimuli correlated with the early portions of an FI clock schedule are punishing, direct evidence of suppression relative to baseline was never collected. Auge examined the effect of response-dependent brief stimulus presentations superimposed over a response-independent FI clock baseline. The rationale behind this procedure was that if the early clock stimuli were aversive, then their response-dependent presentation during the last segment of a response-independent clock should punish responding, i.e., reduce its rate. Furthermore, if the stimulus correlated 
with the final segment of a clock schedule is a conditioned reinforcer, then the responsedependent presentation of that stimulus should increase responding during earlier segments of the interval. An FI 32-s schedule divided into 3 parts was used for the baseline. The first stimulus of the clock was a blue keylight, followed by a horizontal line projected upon the key, and a red keylight was the final stimulus. After several sessions of this baseline, response-dependent brief presentations of the clock stimuli were arranged. In the "red stimulus" condition, the last stimulus, the red keylight, was presented briefly ( 0.5 or $1 \mathrm{~s}$ ) during the first and second thirds of the interval dependent upon a response. In the "blue stimulus" condition, the first stimulus, the blue keylight, was presented briefly during the second and third thirds of the interval dependent upon a response. Finally, in the "horizontal stimulus" condition, the second stimulus, the horizontal line, was briefly presented during the first and third thirds of the interval dependent upon a response. Baseline sessions alternated with the different stimulus conditions. The baseline generated little responding during the first 2 stimuli with most responding occurring to the last stimulus of the interval. When responses produced the red keylight (the final stimulus), responding increased during the first and second thirds of the interval, thus decreasing the post-reinforcement pause (PRP). When a response produced the blue keylight (the first stimulus), responding was suppressed during the final third of the interval relative to baseline. When a response produced the horizontal line (the middle stimulus), responding was suppressed during the final third of the interval relative to baseline. These results warranted the conclusion that the early stimuli in a discrete clocked FI schedule function as S-`s and their presentation can punish 
responding, and the stimulus correlated with reinforcement functions as an $\mathrm{S}+$ and its presentation can reinforce responding.

As the studies on clock stimuli accumulated, the general conclusion was that stimuli early in an interval are aversive and stimuli later in the interval are reinforcing. Although the temporal feature of FI schedules was related to these clock studies in that the clock stimuli were correlated with the passage of time, how adding clock stimuli to an FI schedule affected temporal discrimination of the interval had not been directly investigated. Adding clock stimuli definitely changed responding on these schedules and this behavior change seemed as though it reflected an increase in temporal discrimination of the interval. Palya and Bevins (1990) provided a molar explanation of this temporal discrimination assumption that involves a gradient that extends from the point farthest away from food to the moment of food presentation. This gradient controls responding in two different ways; it inhibits early responding producing avoidance during the first half of the gradient and inhibits avoidance and excites responding during the last half of the gradient (see also Farmer \& Schoenfeld, 1966; Dinsmoor, Lee, \& Brown, 1986). Thus, stimuli associated with portions of an FI do not function as a clock for the entire interval, but rather arrange for a stimulus presented during the latter half of the gradient to serve as a "start signal."

Palya and Bevins (1990) conducted a series of experiments investigating this concept. These experiments used clock stimuli superimposed on a fixed-time (FT; this schedule is similar to the FI, but the reinforcer is presented response-independently at the end of the interval) and FI 60-s schedules. In one phase, the interval was divided into ten periods of $6 \mathrm{~s}$, each of which was correlated with a different stimulus, thus providing a 
clock. In another phase, only one stimulus was presented throughout the interval (conventional FI/FT). Responding was reduced in the early and middle portions of the clocked FI compared to intervals with no clock stimuli. Next, they manipulated the duration of the interval by starting it after any one of the ten clock stimuli, such that the delay to food varied, although food presentation always occurred after the tenth stimulus. For example, the interval could start with the $9^{\text {th }}$ stimulus and then end after the $10^{\text {th }}$ stimulus was presented and the next interval could start at the $3^{\text {rd }}$ stimulus and again end after the $10^{\text {th }}$ stimulus. This procedure was called the "variable start" procedure. The duration of the interval was also manipulated by ending it after any one of the ten stimuli, such that the delay since the most recent food varied. The interval always began with the presentation of the first stimulus but could end after any one of the 10 clock stimuli. This procedure was called the "variable end" procedure. Keypecking obtained during the variable end procedure was similar to that obtained under baseline conditions, while keypecking obtained under the variable start procedure began slightly earlier. Palya and Bevins' findings suggest that by adding clock stimuli to an FI schedule, one is not supplementing the animal's temporal discrimination but rather eliminating the need for it until the "start signal", or the last stimulus in the sequence is presented. If the pigeons are using the last clock stimulus in a discrete clocked FI as a start signal, then arranging for clock stimuli to be a little more ambiguous at that point in the interval should alter the behavior of the birds while also helping to distinguish between these two conclusions. Experiment 1 will do this by presenting clock stimuli with a continuous clock so that moment-to-moment discriminations are difficult and in a response-dependent manner so that the pigeon must attend to some aspect of time in order to peck to produce the clock. 


\section{Drug effects on clocked FI schedules}

Laties and Weiss (1966) suggested that when there are no external stimuli correlated with the passage of time, such as in regular FI schedules, then the temporal discrimination must be due to internal stimuli. They believed they tested this assumption by using FI and clocked FI schedules, in which there were discrete stimuli correlated with the passage of time, as baselines against which they investigated the effects of drugs. During the FI component, the keylight was red throughout the interval. During the clocked FI component, fifths of the interval were differentiated with the following symbols projected on the key: $\Delta, \mathrm{X}, \mathrm{O},+, \square$, respectively. They used the index of curvature to measure the temporal patterning of the behavior. The index of curvature is a measure of temporal patterning of responding on an FI schedule (Fry, Kelleher, \& Cook, 1960). Index of curvature values that are negative indicate that most of the responding occurs at the beginning of the interval, zero values indicate a constant level of responding throughout the interval, and positive values indicate that most of the responding occurs near the end of the interval. They found that some drugs (amphetamine, scopolamine, pentobarbital) reduced the index of curvature under the conventional FI, but not during the clocked FI schedule. Specifically, the pigeons pecked earlier during the FI schedule, thus reducing the index of curvature, but not during the clocked FI schedules. They concluded that behavior maintained by the FI schedule was under the control of internal stimuli, while the behavior maintained by the clocked FI schedule was under the control of the external clock stimuli, and that behavior under external stimulus control (the "stronger" of the two types) was less susceptible to disruption by drugs. 
Odum and Schaal (1999) replicated Laties and Weiss (1966) using morphine and 4 discrete clock stimuli. During the FI 5-min component, the keylight was green throughout the interval. During the clocked FI component, fourths of the interval were differentiated with the following stimuli presented successively: red keylight and flashing houselight, red keylight, white keylight, and blue keylight. Their results replicated Laties and Weiss (1966) in that they found that morphine affected the temporal patterning of behavior under the FI schedule but not under the clocked FI schedule. They found that morphine affected the temporal patterning of behavior generated during the entire FI schedule and the last stimulus (blue keylight) of the clocked FI sequence similarly. That is, the pattern of behavior during the last 75-s stimulus of the clocked FI was disrupted by morphine in a manner similar to that of the regular FI, with low baseline rates early during this stimulus being increased. Based on this finding, they suggested that the effects depended on the function of the FI and clocked FI stimuli rather than the source (internal vs. external) of stimulus control. Specifically, as suggested by the literature on the effects of stimuli in clock schedules, because the first stimuli in the clock sequence were never correlated with food, these stimuli could be considered as S-'s. Drugs failed to alter temporal patterns under the clocked FI schedules not because the pattern was under external temporal stimulus control per se, but rather because drugs typically fail to increase rates in the presence of strong S-'s. Another way of stating this explanation is that the first 3 clock stimuli were not functionally, part of the FI 5-min schedule at all; rather, they merely signaled a long period of non-reinforcement separating the two FI-schedule components of the multiple schedule. No pecks during 
these stimuli would produce food, so the pigeons could wait until the stimulus that was paired with food came on to begin pecking, which is what they did.

\section{Statement of Purpose}

Most studies involving the addition of stimuli correlated with the passage of time in an FI schedule directly investigated the functions of the clock stimuli, while few studies were conducted directly involving how the addition of such stimuli affected the temporal discrimination of the interval. One assumption about clocked FI schedules was that the clock stimuli supplemented the pigeon's discrimination of time, however, previous clocked FI schedules may have eliminated the need for timing by providing discrete clock stimuli such that the pigeon did not have to attend to the early stimuli. It appears that this discrimination of time is resistant to the effects of drugs as indicated by the disruption of timing by drugs during regular FI schedules but not during discrete clocked FI schedules (Odum \& Schaal, 1999 and Laties \& Weiss, 1966). Also, the welldocumented finding of rate-dependency was not found under these clocked schedules, indicating strong stimulus control by the clock stimuli. Morphine alters behavior during the last clock stimulus similarly to behavior generated by a regular FI schedule (Odum \& Schaal, 1999) suggesting that the pigeons do not start "timing" the interval until the last stimulus in the clock sequence is presented. If this is the case, then the baseline FI schedule is no longer equal in time to the clocked FI schedule.

The present procedures attempt to address this inequality problem. Adding clock stimuli to an FI schedule changes the situation as evidenced by the different performances under these types of schedules. In order to more closely equate the clocked FI schedules to the conventional FI schedules in the first experiment, the clock stimuli 
were continuous. The continuous clock stimuli consisted of a flashing houselight in which the rate of flashing changed as time in the interval progressed. This continuous clock made the discrimination between the start and the end of the interval easy, while making moment-to-moment discriminations difficult. These difficult moment-to-moment discriminations gave rise to earlier responding indicating that more of the interval was being timed. In Experiment 2, there were three components consisting of a conventional FI, a discrete clocked FI, and a response-dependent clocked FI. The response-dependent clocked FI required a peck in order to produce the clock stimuli whereas in the discrete clocked FI the clock stimuli were presented as the time in the interval elapsed. Unless a peck occurred, the response-dependent clocked FI was essentially the same as the conventional FI. Some amount of temporal discrimination of the entire interval was necessary in the response-dependent clock condition.

\section{Experiment 1}

\section{METHOD}

\section{$\underline{\text { Subjects }}$}

The subjects were four adult male White Carneau pigeons (Palmetto Pigeon Plant, Sumter, SC) with previous exposure to morphine and various schedules of food reinforcement. After a period of two weeks of unrestricted access to mixed grain, the free-feeding weights of the pigeons were determined as the mean of the last 7 daily weights. The pigeons were then maintained at $70 \%$ of their free-feeding weight. They were housed in a temperature-controlled colony under a light:dark cycle of 12:12 hr with unrestricted access to water and digestive grit. 


\section{$\underline{\text { Apparatus }}$}

Four custom-made experimental chambers, constructed of wood with aluminum front panels, were located in a small, darkened room. The internal dimensions of each chamber were $33 \mathrm{~cm}$ across the front panel, $31 \mathrm{~cm}$ from the front panel to the back wall, and $37.5 \mathrm{~cm}$ from the floor to ceiling. Three $2.1 \mathrm{~cm}$ diameter translucent plastic response keys were located on the front panel $26 \mathrm{~cm}$ above the floor. The key required a force of $0.19 \mathrm{~N}$ to record a response. Only the center key was used and the side keys remained dark throughout the experiment. The key could be lit from behind with blue, white, green, red, and amber light. A 28-V 1.1-W lamp was located $7 \mathrm{~cm}$ above the center key, which served as the houselight. A rectangular aperture was located $16 \mathrm{~cm}$ below the center key and provided access to a solenoid-operated food hopper filled with mixed grain. During hopper presentations, the aperture was lit with white light and the houselight and keylight were extinguished. Extraneous sounds were masked by white noise and chamber ventilation fans. All events were programmed and data were collected on a MS-DOS-based 80386 microcomputer using the Smart Cumulative Recorder and a MS-DOS-based 80486 microcomputer, using Medstate Notation (MED Associates, Inc. \& Tatham, 1991), which was located in an adjacent room.

$\underline{\text { Procedure }}$

Experimental sessions occurred at approximately the same time 6 - 7 days a week. Pretraining consisted of gradually increasing the FI schedule from $1 \mathrm{~min}$ up to $5 \mathrm{~min}$ with the corresponding stimuli described below. The pigeons pecked keys on a multiple FI 5min and clocked FI 5-min schedule of food presentation with strictly alternating components separated by a 1-s blackout, during which the chamber was dark and pecks 
had no consequences. Pigeons were placed in a darkened chamber for 10 minutes prior to the start of the session. Each component was presented 5 times and the duration of each session was approximately one hour. If the pigeons did not peck within 3 min after the end of the 5-min interval, the component ended and the next component began after the 1-s blackout.

During the FI component, the keylight was lit amber and the houselight was on throughout the interval. The first peck after 5 min produced 4-s access to mixed grain. During the clocked FI component, the keylight was lit blue and the houselight flashed on and off. The rate of flashing increased continuously as the interval elapsed. The houselight was on for $4.88 \mathrm{~s}$ and then was turned off for $4.84 \mathrm{~s}$, on for $4.80 \mathrm{~s}$, off for 4.76 $\mathrm{s}$, etc., such that by the end of the interval, the houselight flashed on and off every $0.12 \mathrm{~s}$ (see Figure 1). This procedure produced a terminal flicker rate of $8.34 \mathrm{cps}$, which allowed the flashing to be detectable by human observers. Furthermore, Hendricks (1966) examined the critical flicker fusion frequencies for three pigeons. Using a conditioned suppression procedure, it was determined that pigeons' flicker fusion frequencies ranged from 40 to $75 \mathrm{cps}$ depending upon the stimulus intensity. Thus it was very likely that the pigeons in the present study were able to detect the flashing at the end of the interval. The first peck after 5 min produced 4-s access to mixed grain.

\section{Drug preparation and administration}

Drug testing began when overall response rates and indices of curvature were stable from session to session as judged by visual inspection (showed no increasing or 
-

$\longrightarrow \%$ previous

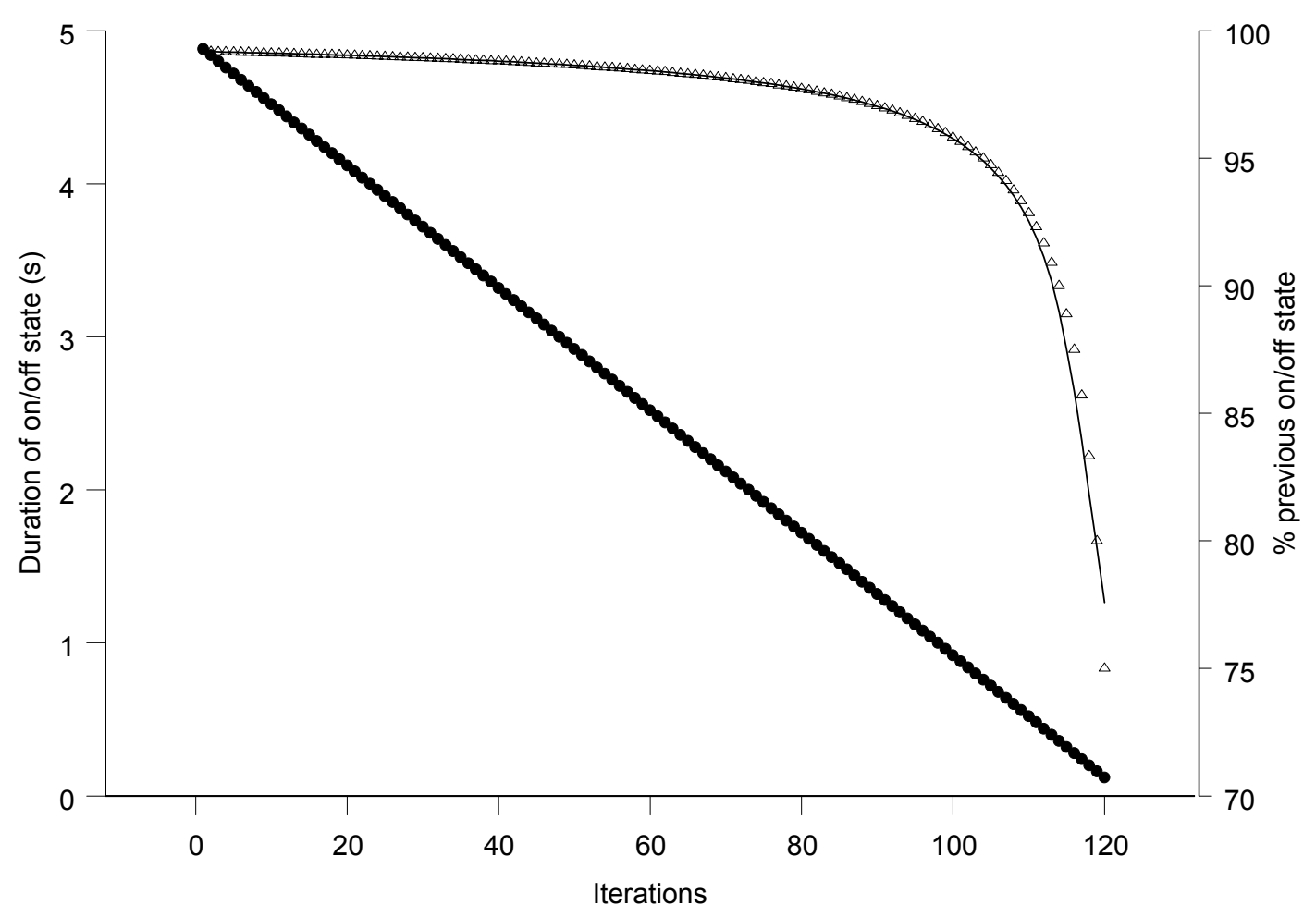

Figure 1. Duration of houselight on/off state in s (closed circles) as it changes throughout the 5 min interval plotted as a function of iterations during a single interval. The open triangles indicate the percent of the previous state for each iteration. 
decreasing trends nor extreme variability). Pigeons were weighed prior to and after experimental sessions and drug or saline tests were not conducted if weights were not within $10 \mathrm{~g}$ of the $70 \%$ free feeding weights. Morphine $(1.0,3.0,5.6$, and $10.0 \mathrm{mg} / \mathrm{kg}$ ) and d-amphetamine $(0.1,0.3,1.0,3.0$, and $5.6 \mathrm{mg} / \mathrm{kg})$ were dissolved in isotonic saline. Injections were administered intramuscularly in a volume of $1.0 \mathrm{ml} / \mathrm{kg}$ immediately prior to session onset. Sessions began with a 10-min period during which pigeons were placed in a darkened chamber. Drug or saline administrations were separated by at least 3 sessions conducted under baseline conditions. The session that immediately preceded a morphine, $d$-amphetamine, or saline injection was designated a control session. Data from these sessions represented baseline, non-drug performance, against which the effects of drugs were assessed. Drugs were not tested unless a control session occurred the previous day. Three to four determinations of each dose occurred unless doses completely suppressed behavior, in which case fewer than three determinations occurred. A mid-range dose (3.0 mg/kg morphine) was given repeatedly prior to dose-response testing. This procedure was thought to reduce the novelty of the effect of the drug. The first several administrations of drug often produce effects that are not typical of later effects, so these preliminary determinations were discarded. Both d-amphetamine and morphine along with saline were administered in a mixed-order.

$\underline{\text { Data analysis }}$

Overall response rates (responses per minute) were computed for each component by dividing total pecks in an FI component by total time during that component. Responses were also collected separately for the two components in ten 30-s bins corresponding to successive tenths of the interval. Response rates were computed in each 
tenth. In addition, a cumulative record program collected all responses, reinforcers, and the time in which they occurred throughout the experiments.

The index of curvature (Fry, Kelleher, \& Cook, 1960) was computed as a measure of temporal patterning of behavior. Indices of curvature were computed separately for the FI schedules and clocked FI schedules and only if at least 20 responses occurred during both components for the entire session. The index of curvature was calculated by the following formula:

$$
I=\frac{(n-1) R_{n}-2 \sum_{i=1}^{n-1} R_{i}}{n R_{n}} \quad \text { where } \mathrm{n}=\text { bins and } \mathrm{R}=\text { time intervals. }
$$

Negative index of curvature values indicate that most responses occurred during the early portion of the interval, while positive values indicate that most responding occurred during the end of the interval. If there was an even distribution of responses throughout the interval, the index value will equal 0 . The number of bins included in the analysis can affect the outcome of the calculation. Generally the more bins, the greater the sensitivity to changes in the index.

Data were typically presented in dose-effect functions, in which drug dose is plotted on the x-axis and response rate or index of curvature is plotted on the y-axis. Effects of drugs on response rates within intervals are also presented.

\section{RESULTS}

\section{d-Amphetamine}

The effects of d-amphetamine on overall patterning of behavior as measured by the index of curvature are depicted in the left panels of Figure 2 for Pigeons P866, P435, P585, and P582. The filled circles represent the mean index of curvature across all 


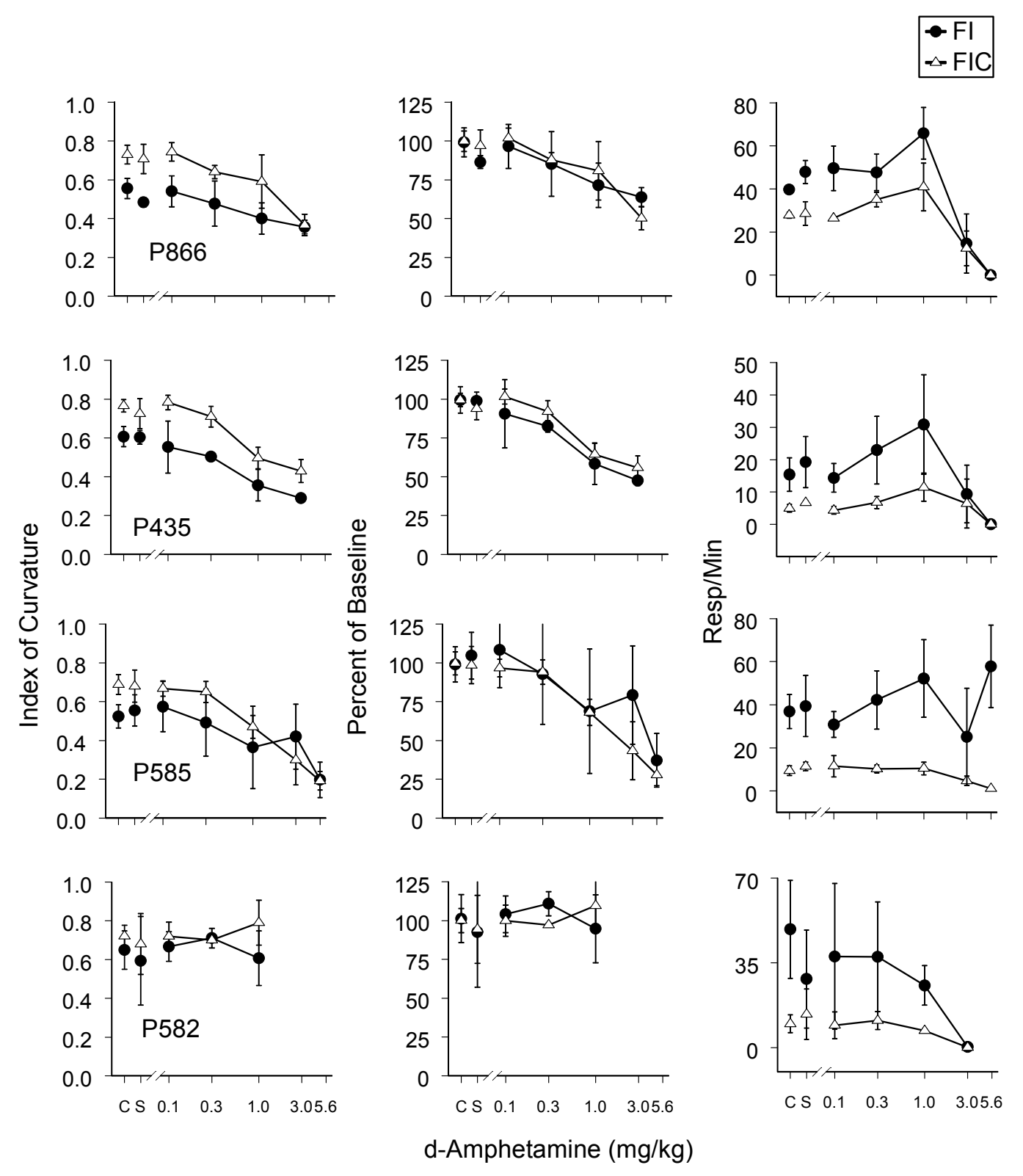

Figure 2. Effects of d-amphetamine on the index of curvature (left column), percent of baseline index of curvature (middle), and rates of key pecking (right column) calculated for the FI 5-min and clocked FI 5-min components of the multiple schedule for each pigeon (rows). Unconnected points show mean rates for all control sessions (C) and determinations of saline (S). Lines connect points showing mean rates for determinations of d-amphetamine and vertical bars represent one standard deviation above and below means. 
determinations (+/- one standard deviation) under the FI components and the open triangles represent the mean index of curvature ( $+/$ - one standard deviation) under the clocked FI components. In general, there was a dose-dependent decrease in the index of curvature for both the FI and the clocked FI components. The percent of baseline index of curvature graphs show that the overall effect for both components were similar. The control values for the clocked FI components were always greater than the control values for the FI components, thus indicating that the pigeons began responding later in the interval under the clocked FI components. These values during the clocked FI components ranged from approximately 0.70 to 0.75 , while during the FI components they ranged from approximately 0.50 to 0.65 . Saline did not have a reliable effect on the pattern of behavior in either condition. d-Amphetamine did not alter the index of curvature for P582 at the lowest doses. This bird's behavior was completely suppressed by $3.0 \mathrm{mg} / \mathrm{kg}$ of d-amphetamine.

The effects of d-amphetamine on the overall response rate (responses/min) are depicted in the right panels of Figure 2. The control response rate was always higher in the FI components than in the clocked FI components. It varied from approximately 18 to 50 responses per minute in the FI components and from 5 to 28 responses per minute in the clocked FI components. There was no effect of saline on the response rates. For three pigeons, there was a tendency for d-amphetamine to increase response rates under the FI components (filled circles) at moderate doses. No such tendency was observed under the clocked FI components (open triangles) or for P582 under either schedule. For this bird, and for the others under the clocked FI components, only decreases in overall response rates were observed. P582 was also most sensitive to the rate-decreasing effects 


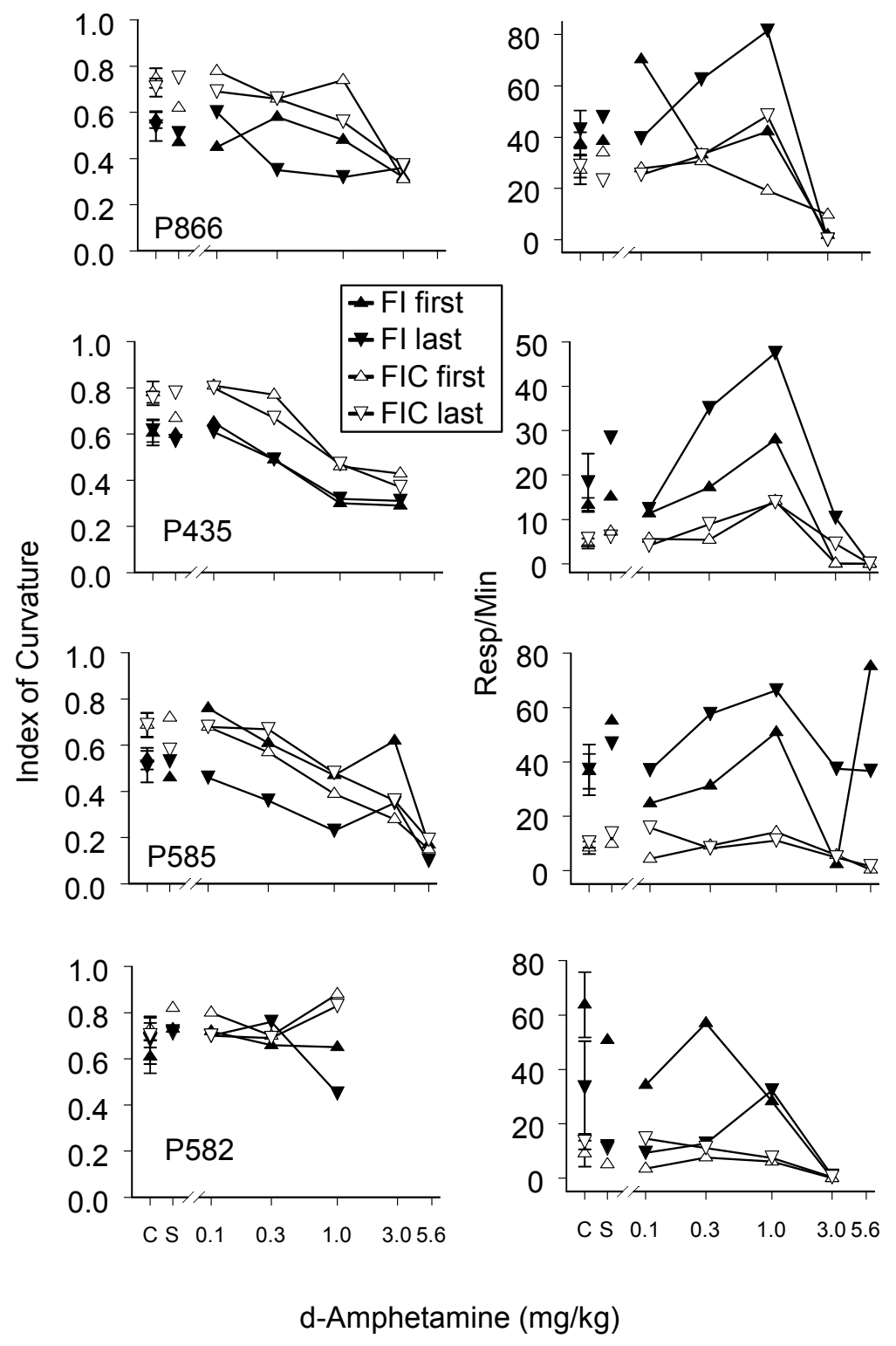

Figure 3. Effects of the first and last determinations of d-amphetamine on the index of curvature (left column), and rates of key pecking (right column) calculated for the FI 5min and clocked FI 5-min components of the multiple schedule for each pigeon (rows). Unconnected points show mean rates for all control sessions (C) and determinations of saline (S). 
of d-amphetamine; $3.0 \mathrm{mg} / \mathrm{kg}$ suppressed response rates completely for this bird, and 5.6 $\mathrm{mg} / \mathrm{kg}$ was not tested.

To determine whether repeated dose-effect testing produced tolerance (or sensitization) to the drug, the indices of curvature (left panels) and overall response rate (right panels) generated for the first and last determination of each dose including saline were plotted and can be seen in Figure 3. The two control points represent the mean of the first half and the last half of all the control days or days before drug administration. The upward triangles represent the data from the first determination of each dose, while the downward triangles represent the data from the last determination of each dose. The filled triangles represent the behavior under the FI components and the open triangles represent the behavior under the clocked FI components. There were no differences in the indices of curvature between the first half and the last half of control points for any of the birds. An accepted definition of tolerance is a shift to the right in the dose effect curve, while sensitization is a shift to the left (Branch, 1993). Neither of these shifts occurred. Overall, the indices of curvature were not systematically different during the first or last determination. For 2 of the birds, P866 and P585, the index of curvature during the FI component under the first determination of drug was higher than the index of curvature generated during the last determination. For the other 2 birds, P435 and P582, there was no effect of dose determination during the FI component. During the clocked FI components, indices were not substantially or systematically different for the determinations of the drug.

For response rates, there was no systematic difference between the first half and last half of the control sessions except for P582 during the regular FI component, where 
the response rates were higher during the first half of the control sessions. The saline points followed this same trend as well. This result indicates a baseline shift during the course of the experiment or that response rates gradually decreased as the experiment proceeded. For 3 of the birds, the last determination of d-amphetamine generated higher response rates under the FI components than did the first determination of drug, with the exception of $0.1 \mathrm{mg} / \mathrm{kg}$ for P866 and $5.6 \mathrm{mg} / \mathrm{kg}$ for P585 where the first determination produced a higher response rate. For P582, more responding occurred after the first determinations of $0.1 \mathrm{mg} / \mathrm{kg}$ and $0.3 \mathrm{mg} / \mathrm{kg}$ than after the last determinations. There was a baseline shift as indicated by the difference in control points, suggesting that this difference in responding may reflect baseline differences rather than differences in drug effects. At the doses of $1.0 \mathrm{mg} / \mathrm{kg}$ and $3.0 \mathrm{mg} / \mathrm{kg}$, there was no difference between the determinations.

Mean total pecks (+/- 1 s.d.) are plotted for tenths of the interval for each bird in Figure 4. The filled circles represent pecks during the FI components and the open triangles represent pecks during the clocked FI components. For bird P866 (first panel), the typical scallop type pattern of responding occurred under saline conditions for the clocked FI component, with little variation. In the FI component, the behavior followed a positively accelerated curve with acceleration beginning in the $5^{\text {th }}$ tenth of the interval. dAmphetamine produced slight increases in early-interval rates in both components and decreased high rates at the higher doses. The variability in responding increased during the FI component after $0.1 \mathrm{mg} / \mathrm{kg}$ of d-amphetamine. There was a tendency for the bird to start responding earlier in the interval as evidenced by increases in pecks in the $3^{\text {rd }}$ and $4^{\text {th }}$ tenth of the interval of the FI component after $0.3 \mathrm{mg} / \mathrm{kg}$ d-amphetamine. These 


$$
\begin{array}{llll}
\text { P866 } & \text { P435 } & \text { P585 } & \text { P582 }
\end{array}
$$
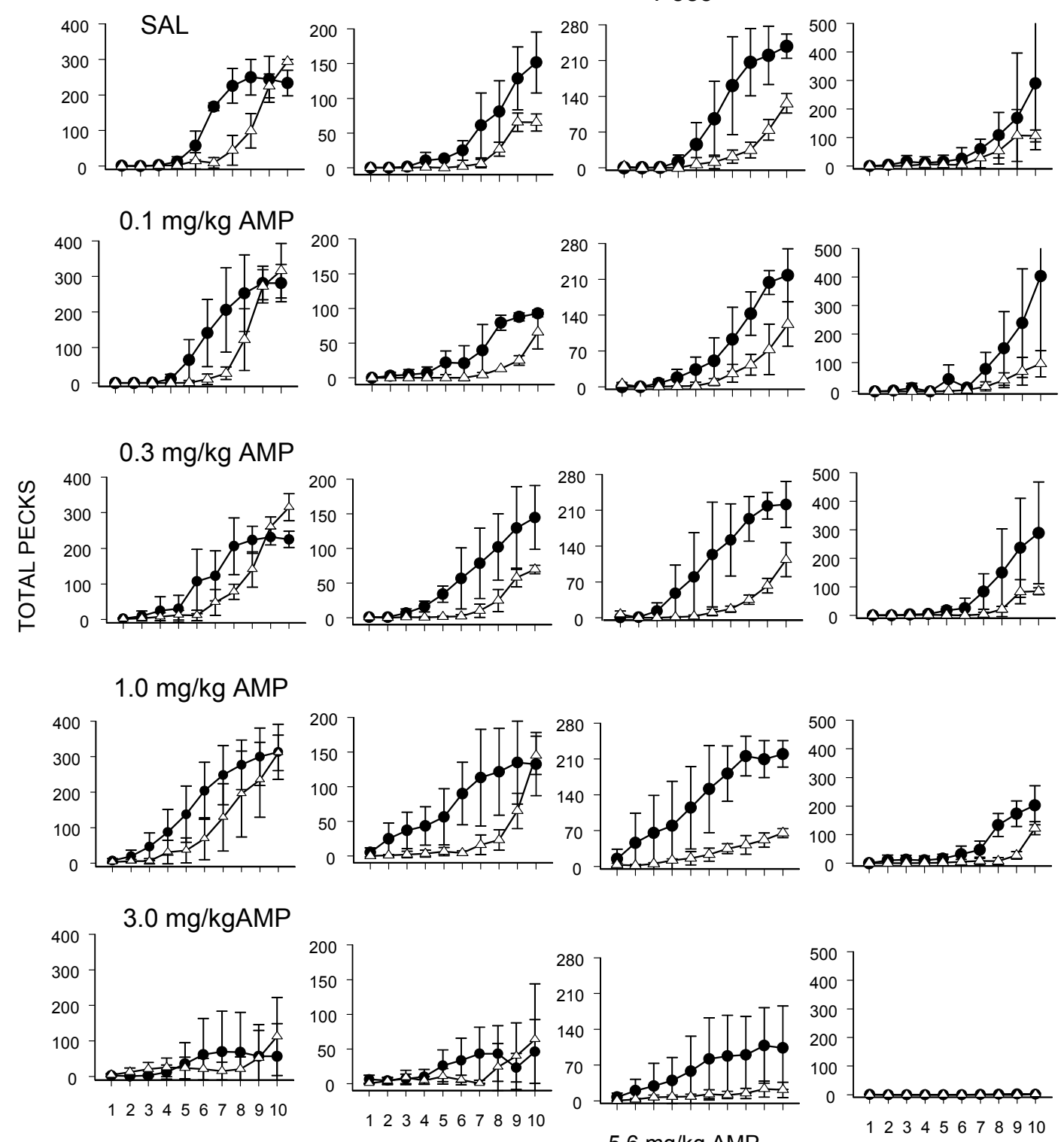

TENTHS OF THE INTERVAL

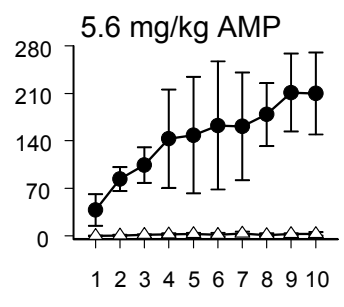

Figure 4. Total pecks in consecutive 30-s segments of FI 5-min (filled circles) and clocked FI 5-min (open triangles) intervals obtained under saline, $0.1 \mathrm{mg} / \mathrm{kg}, 0.3 \mathrm{mg} / \mathrm{kg}$, $1.0 \mathrm{mg} / \mathrm{kg}, 3.0 \mathrm{mg} / \mathrm{kg}$, and $5.6 \mathrm{mg} / \mathrm{kg}$ d-amphetamine. Error bars represent $+/$ - one standard deviation. 
increases in early-interval response rates, combined with decreases in late-interval response rates, produced the decreases in the index of curvature seen in Figure 3. Responding in the clocked FI component followed this same pattern as responding under saline conditions. This bird started pecking during the $2^{\text {nd }}$ tenth of the interval after 1.0 $\mathrm{mg} / \mathrm{kg}$ of d-amphetamine followed by an almost constant trend of an increasing rate of responding across the remaining tenths of the interval in the FI component. During the clocked FI component, responding was characterized by the scalloped pattern with more variation around the mean and earlier interval responding compared to behavior after saline administration. $3.0 \mathrm{mg} / \mathrm{kg} \mathrm{d}$-amphetamine suppressed responding in both components.

For P435 (second column) under saline conditions, the typical scallop pattern was obtained in both the FI and clocked FI components, with more responding occurring in the FI component. Early-interval rates were only increased in the FI component at 1.0 $\mathrm{mg} / \mathrm{kg}$. No differences were obtained in responding in the clocked FI component between the administration of $0.1 \mathrm{mg} / \mathrm{kg}$ or $0.3 \mathrm{mg} / \mathrm{kg}$ and saline. $1.0 \mathrm{mg} / \mathrm{kg} \mathrm{d}-$ amphetamine produced a sharper scallop type pattern with an increase in responding during the last tenth of the interval for the clocked FI component. During the FI component, responding began at the $2^{\text {nd }}$ tenth and slightly increased with each tenth. The most variation around the mean in responding occurred in this condition under the FI component. A dose of $3.0 \mathrm{mg} / \mathrm{kg} \mathrm{d}$-amphetamine resulted in suppressed responding in both the FI and clocked FI components. Responding during the FI component started earlier but was suppressed relative to that under saline conditions. 
For bird P585 (third column) responding showed the typical scalloped pattern of responding in both the clocked FI and FI components under saline conditions. More variation about the mean in responding occurred during the FI component and the scallop was not as sharp as obtained in the clocked FI component. Overall, d-amphetamine increased early-interval responding during the FI component at all doses except 0.1 $\mathrm{mg} / \mathrm{kg}$ and some early-interval responding during the clocked FI component occurred at $1.0 \mathrm{mg} / \mathrm{kg}$ and $3.0 \mathrm{mg} / \mathrm{kg}$. Variation about the mean in responding increased during the clocked FI component after the administration of $0.1 \mathrm{mg} / \mathrm{kg}$ d-amphetamine. $0.3 \mathrm{mg} / \mathrm{kg}$ d-amphetamine produced some earlier responding and increased variation during the FI component as compared to saline conditions. After $1.0 \mathrm{mg} / \mathrm{kg} \mathrm{d}$-amphetamine, responding started in the $1^{\text {st }}$ tenth of the interval and increased as the tenths increased until the $8^{\text {th }}$ tenth where responding remained at the same level until the last tenth during the FI component. Responding in the clocked FI component started in the $3^{\text {rd }}$ tenth of the interval and slightly increased throughout the interval. Overall, responding was suppressed during this condition. A few responses were made during the clocked FI component after a dose of $3.0 \mathrm{mg} / \mathrm{kg}$ d-amphetamine, while responding in the FI component started in the $1^{\text {st }}$ tenth of the interval and increased with each tenth until a slight decrease in the last tenth. Also, there was a lot of variation around each mean in this condition. A dose of $5.6 \mathrm{mg} / \mathrm{kg}$ d-amphetamine almost completely suppressed responding in the clocked FI component. In the FI component, responding began in the $1^{\text {st }}$ tenth and increased with each increasing tenth of the interval. Responding increased for the earlier tenths of the interval compared to responding under saline conditions. 
P582's (last panel) responding differed from that of the other birds in that there were considerably fewer responses overall. Under saline, pecking occurred in a scalloped pattern in both the clocked FI and FI components. Response rates were higher under the FI condition. The main effect of d-Amphetamine was an increase in early-interval responding only at the $1.0 \mathrm{mg} / \mathrm{kg}$ dose and only in the FI condition. This dose also suppressed later-interval responding. A dose of $0.1 \mathrm{mg} / \mathrm{kg}$ d-amphetamine produced no change in responding in the clocked FI component. In the FI component, there was a burst of responding in the $5^{\text {th }}$ tenth of the interval. There was also an increase in the variation around the mean at the last tenth of the interval compared to that during saline administrations. There was no change in responding during either the FI or the clocked FI components after $0.3 \mathrm{mg} / \mathrm{kg}$ d-amphetamine compared to responding under saline conditions. The only effect of $1.0 \mathrm{mg} / \mathrm{kg}$ d-amphetamine on responding was during the FI component, where there was less variation in responding about the mean compared to that under saline conditions. Under $3.0 \mathrm{mg} / \mathrm{kg}$ d-amphetamine, responding was almost completely suppressed in both the FI and the clocked FI components.

The rate-dependent effects of d-amphetamine are apparent in Figure 4 as increases in responding early in the intervals and decreases in responding near the ends of the intervals. For P866, P435, and P582, this effect can be observed after doses of 0.3 $\mathrm{mg} / \mathrm{kg}, 1.0 \mathrm{mg} / \mathrm{kg}$, and $3.0 \mathrm{mg} / \mathrm{kg}$ and at all doses of d-amphetamine for P585. The dose of $1.0 \mathrm{mg} / \mathrm{kg}$ produced the clearest effect in all birds in both the FI and the clocked FI components, with no suppression in responding, which occurred with the dose of 3.0 $\mathrm{mg} / \mathrm{kg}$. Overall, the changes in response patterning were more likely and larger in the FI component than in the clocked FI component. 


\section{Morphine}

The effects of morphine on the index of curvature appear in the left panels of Figure 5. In general, there was a dose-dependent decrease in the index for both the FI and the clocked FI components, except during the clocked FI component for P435 where there was no reliable effect of morphine on the index of curvature in the clocked FI component. This result is supported by the similarity of the curves in the percent of baseline index of curvature graphs. The control values for the clocked FI components were always greater, albeit slightly, than the control values for the FI components. The values obtained during the clocked FI components ranged from approximately 0.70 to 0.75, while during the FI components they ranged from approximately 0.49 to 0.65 . Saline did not have an effect on the behavior in either condition.

The overall effect of morphine on response rates during the FI and clocked FI components was a decrease with the administration of the higher doses with the following exceptions. Response rates increased under the $1.0 \mathrm{mg} / \mathrm{kg}$ dose of morphine in the FI component occurred for P866. For P585 there was a dose-dependent increase in responding during the clocked FI component except at the highest dose of morphine where there was no effect of drug on response rate. The control response rate was always higher in the FI components than in the clocked FI components. The rate varied from approximately 20 to 45 responses per minute in the FI components and from 9 to 26 responses per minute in the clocked FI components. Saline had no effect on the response rates. 


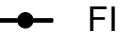

$\rightarrow$ FIC
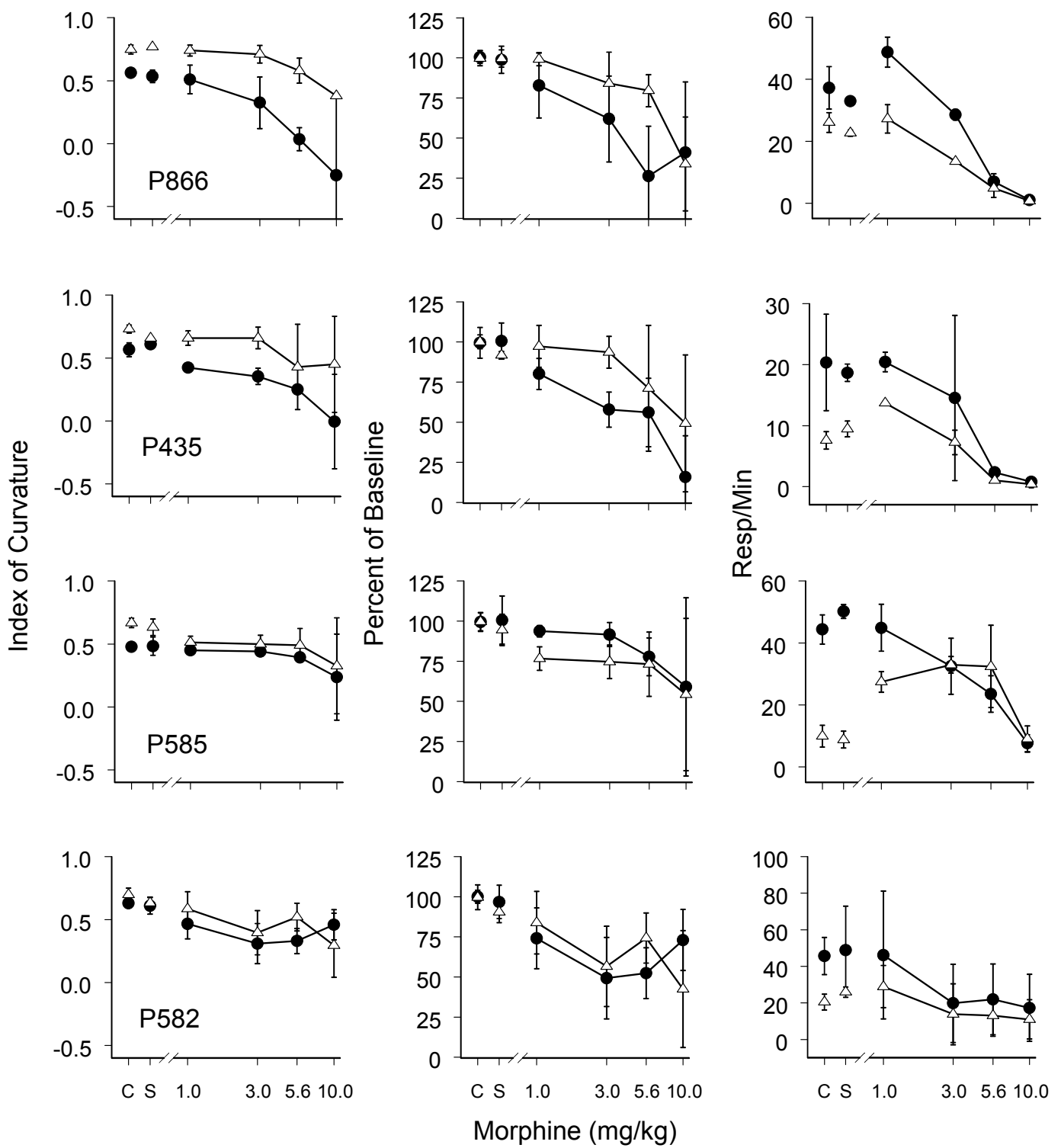

Figure 5. Effects of morphine on the index of curvature (left column), percent of baseline for the index of curvature (middle), and rates of key pecking (right column) calculated for the FI 5-min and clocked FI 5-min components of the multiple schedule for each pigeon (rows). Unconnected points show mean rates for all control sessions (C) and determinations of saline $(\mathrm{S})$. Lines connect points showing mean rates for determinations of morphine and vertical bars represent one standard deviation above and below means. 

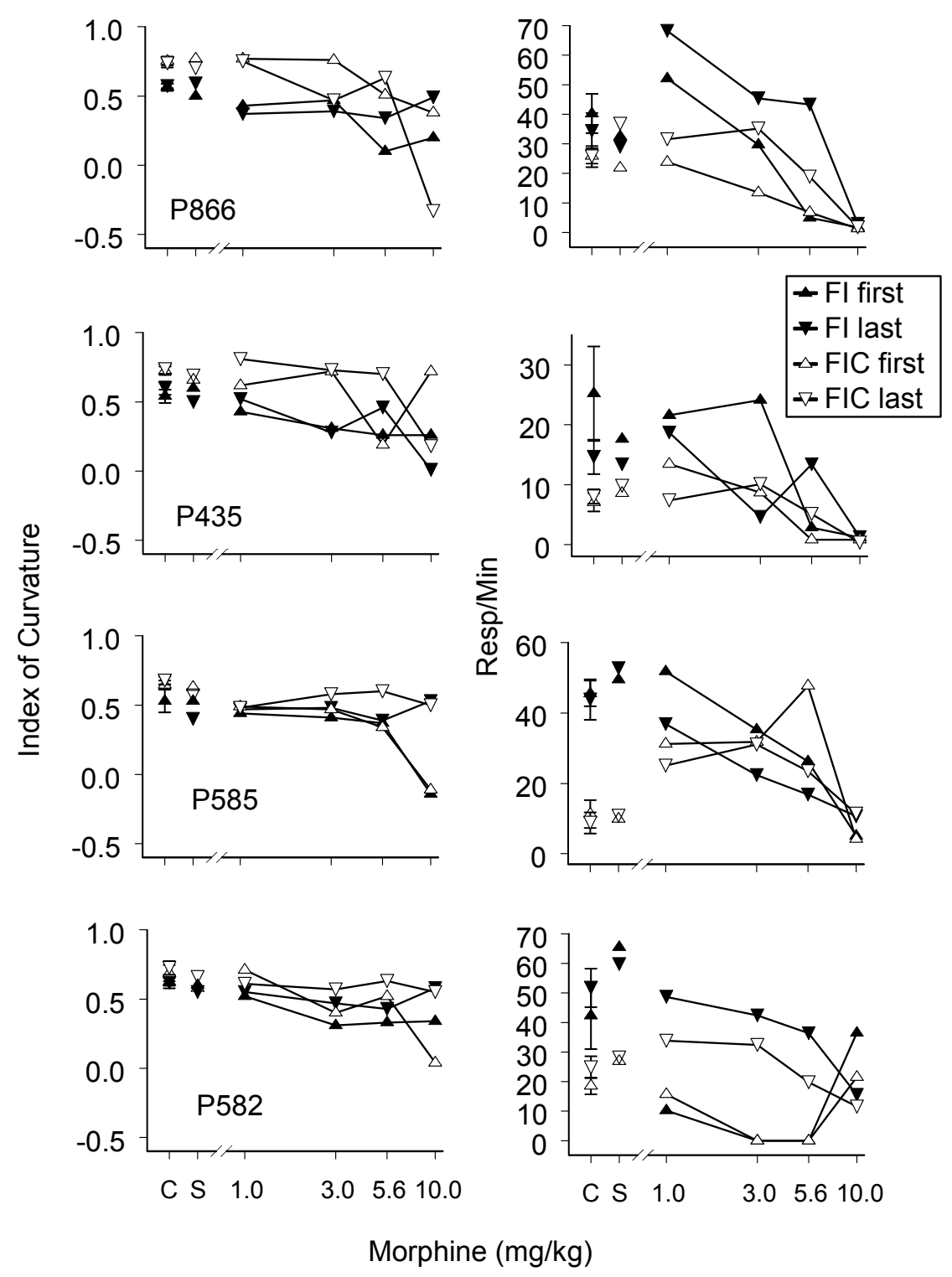

Figure 6. Effects of the first and last determinations of morphine on the index of curvature (left column), and rates of key pecking (right column) calculated for the FI 5min and clocked FI 5-min components of the multiple schedule for each pigeon (rows). Unconnected points show mean rates for all control sessions (C) and determinations of saline $(\mathrm{S})$. 
Figure 6 shows the indices of curvature (left panels) and overall response rate (right panels) generated for the first and last determination of each dose. Overall, neither a shift to the right or left in the dose effect curve for the index of curvature was observed, indicating no tolerance or sensitization to morphine. For P866 and P582, a slight tolerance to morphine could have developed as response rates produced after the last administration of doses of morphine were higher for both FI components. However, P585's response rates were higher after the first administration of morphine doses but only during the regular FI component. This type of shift may indicate sensitization, but this conclusion is complicated by the unusual effect of $10.0 \mathrm{mg} / \mathrm{kg}$ across determinations.

Mean total pecks (+/- one standard deviation) are plotted for tenths of the interval for each bird in Figure 7. The filled circles represent pecks during the FI components and the open triangles represent pecks during the clocked FI components. For bird 866 (first column), the scalloped pattern of responding was obtained in the clocked FI component with responding beginning in the $5^{\text {th }}$ tenth of the interval under saline conditions. In the FI condition, responding began in the $6^{\text {th }}$ tenth of the interval and continued to increase with the highest responding in the $8^{\text {th }}$ tenth of the interval and then slightly decreasing in the $9^{\text {th }}$ and $10^{\text {th }}$ tenths of the interval. Intermediate doses of morphine increased early-interval responding in the FI component and slightly increased responding in the clocked FI components. There was no effect on responding in the clocked FI condition after a dose of $1.0 \mathrm{mg} / \mathrm{kg}$ morphine. However, in the FI condition, responding started earlier ( $3^{\text {rd }}$ tenth) with more variation in responding around the mean. Responding started earlier in both components with suppressed responding later in the interval during the FI component with the administration of $3.0 \mathrm{mg} / \mathrm{kg}$ morphine. The 


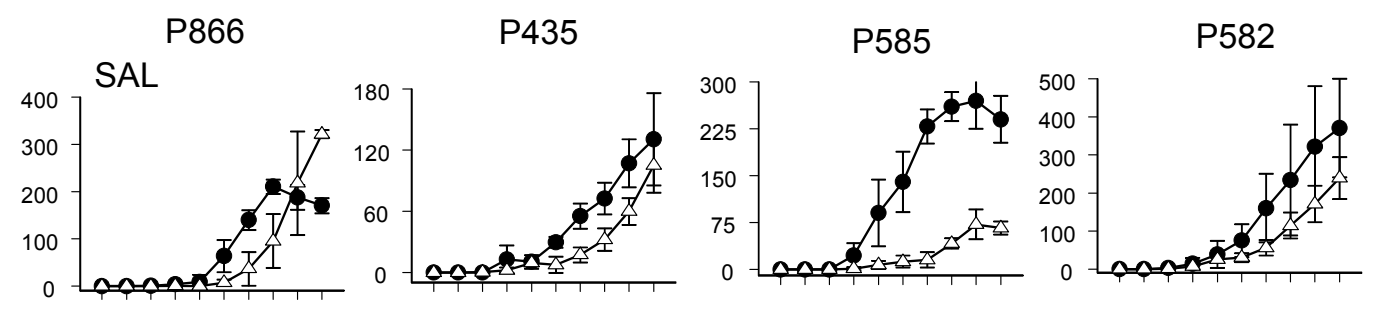

$1.0 \mathrm{mg} / \mathrm{kg} \mathrm{MOR}$
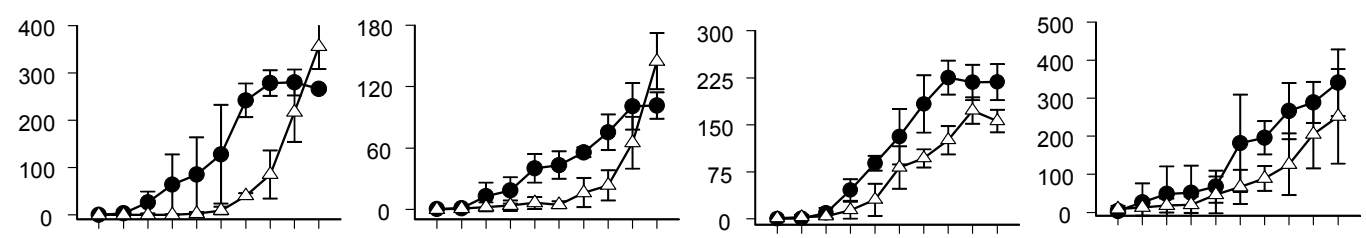

$3.0 \mathrm{mg} / \mathrm{kg} \mathrm{MOR}$
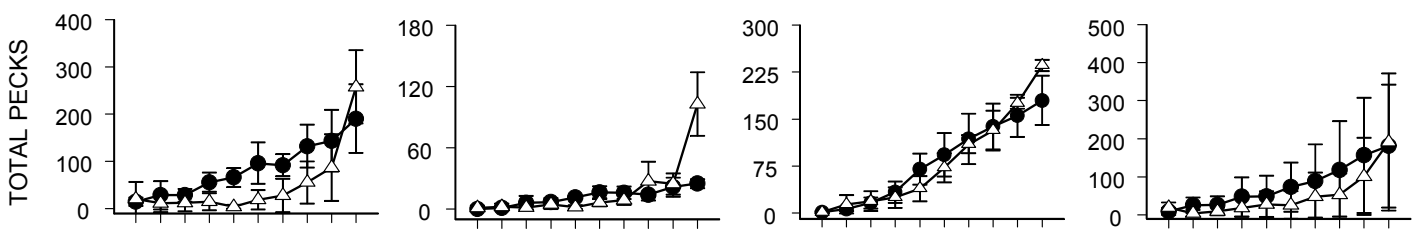

$5.6 \mathrm{mg} / \mathrm{kg} \mathrm{MOR}$
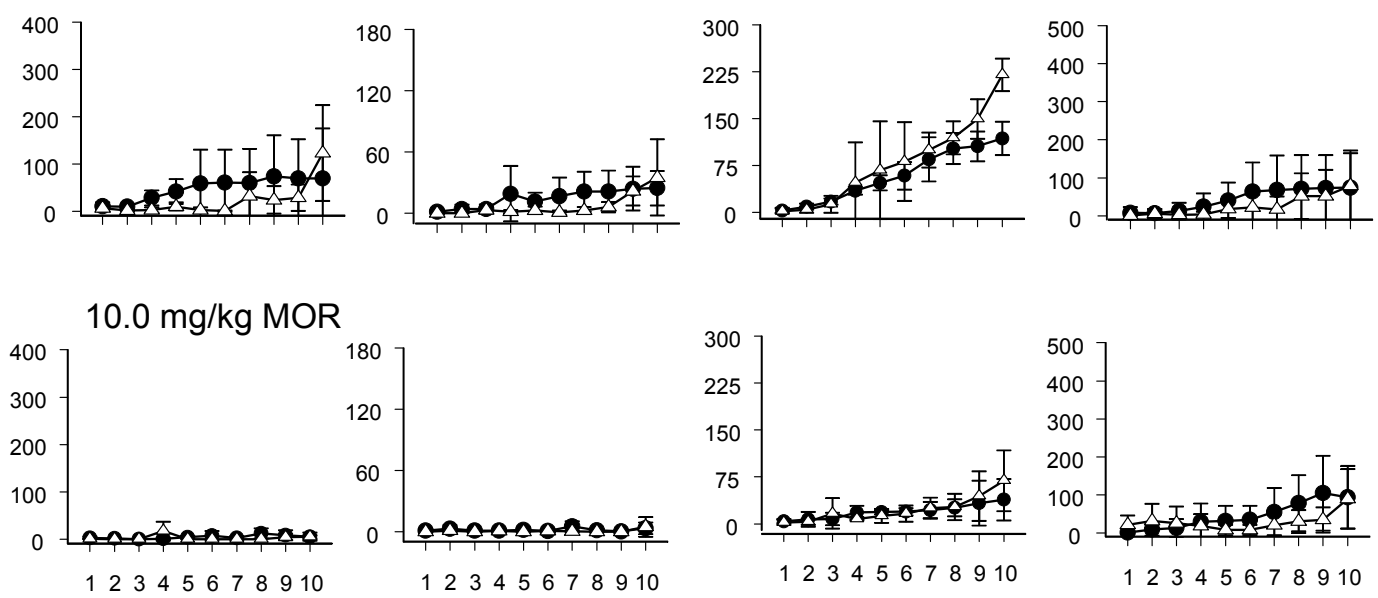

TENTHS OF THE INTERVAL

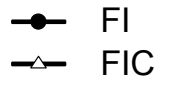

Figure 7. Total pecks in consecutive 30-s segments of FI 5-min (filled circles) and clocked FI 5-min (open triangles) intervals obtained under saline, $1.0 \mathrm{mg} / \mathrm{kg}, 3.0 \mathrm{mg} / \mathrm{kg}$, $5.6 \mathrm{mg} / \mathrm{kg}$, and $10.0 \mathrm{mg} / \mathrm{kg}$ morphine. Error bars represent $+/$ - one standard deviation. 
dose of $5.6 \mathrm{mg} / \mathrm{kg}$ morphine produced earlier responding along with suppression in the overall responding in the later tenths of the interval during both components. Only a few responses occurred after the $10.0 \mathrm{mg} / \mathrm{kg}$ dose of morphine.

For bird 435 (second column), under saline conditions, responding in both the clocked FI and FI components followed the scalloped pattern of responding with responding beginning in the $4^{\text {th }}$ tenth of the interval. The main effect of morphine on this bird's responding was an increased in the early parts of the interval during the FI component. A dose of $1.0 \mathrm{mg} / \mathrm{kg}$ morphine produced responding that began earlier (in the $3^{\text {rd }}$ tenth) during both the clocked FI and FI components. Suppression of responding in the FI component compared to that under saline conditions was obtained after 3.0 $\mathrm{mg} / \mathrm{kg}$ morphine. The same was true for the clocked FI component except for the last tenth of the interval. Again, $5.6 \mathrm{mg} / \mathrm{kg}$ morphine suppressed responding in both components. The scalloped pattern of responding persisted in the clocked FI component, while there was more equal responding across the tenths for the FI component. There were only a few responses in the last tenth of the interval for the clocked FI component and in the $2^{\text {nd }}, 5^{\text {th }}, 7^{\text {th }}$, and 10 tenths of the interval for the FI component after the 10.0 $\mathrm{mg} / \mathrm{kg}$ dose of morphine.

For bird 585 (third column), responding started in the $5^{\text {th }}$ tenth of the interval and continued to increase until similar responding was obtained in the $9^{\text {th }}$ and $10^{\text {th }}$ tenth of the interval for the clocked FI component. Responding in the FI component started in the $4^{\text {th }}$ tenth of the interval and increased until the $9^{\text {th }}$ tenth of the interval followed by a slight decrease in the last tenth of the interval. All doses of morphine increased early-interval responding in both components. Responding started 1 tenth earlier in the interval for 
both the clocked FI and FI components after $1.0 \mathrm{mg} / \mathrm{kg}$ morphine. The shape of responding remained similar in the clocked FI component but with more responding in each tenth of the interval. In the FI component, responding was similar compared to that generated under saline conditions. After the administration of $3.0 \mathrm{mg} / \mathrm{kg}$ morphine, responding started in the $2^{\text {nd }}$ tenth and then gradually increased with each tenth in the clocked FI and FI components. Rates of responding were higher in each tenth except the $1^{\text {st }}$ than under saline conditions in the clocked FI component. The effects of the 5.6 $\mathrm{mg} / \mathrm{kg}$ morphine dose in both the FI and clocked FI components were similar to those with $3.0 \mathrm{mg} / \mathrm{kg}$ morphine. A dose of $10.0 \mathrm{mg} / \mathrm{kg}$ morphine produced a few responses, which were made in each tenth in the FI component, while responding followed a scalloped pattern in the clocked FI component but with fewer responses made than under any other dose of morphine or saline conditions.

Responding after the administration of saline for bird 582 (last column) followed a scallop type pattern in both the clocked FI and FI components. Morphine increased responding in the early portions of both the FI and clocked FI components at intermediate doses. Higher doses of morphine suppressed overall responding in both components. After a $1.0 \mathrm{mg} / \mathrm{kg}$ dose of morphine, responding started earlier but retained a similar shape as that under saline conditions for the clocked FI component. Responding in the FI component started earlier and was enhanced until the $7^{\text {th }}$ tenth of the interval where responding was maintained at the same levels as that under saline conditions.

Administration of $3.0 \mathrm{mg} / \mathrm{kg}$ morphine produced similar effects on responding as 1.0 $\mathrm{mg} / \mathrm{kg}$ morphine until the $6^{\text {th }}$ tenth of the interval where responding was suppressed compared to that under saline conditions in the FI component. The only change from 1.0 
to $3.0 \mathrm{mg} / \mathrm{kg}$ morphine in the clocked FI component was one of suppression of responding with a similar shape of the curve. The dose of $5.6 \mathrm{mg} / \mathrm{kg}$ morphine suppressed responding in both components except for a few responses in the earlier tenths of the interval. $10.0 \mathrm{mg} / \mathrm{kg}$ morphine produced similar effects on responding. Almost complete suppression of responding was the effect in the clocked FI component except for responses in the last tenth of the interval. There was more overall responding in the FI component compared to the clocked FI component.

Figure 7 also provides information concerning the rate-dependent effects of morphine. For P866, earlier interval responding occurred at the doses $1.0 \mathrm{mg} / \mathrm{kg}$ during the FI component and $3.0 \mathrm{mg} / \mathrm{kg}$ and $5.6 \mathrm{mg} / \mathrm{kg}$ for both FI and clocked FI components. The rate-dependent effect only occurred at the dose of $1.0 \mathrm{mg} / \mathrm{kg}$ during the FI component for P435. The doses of $3.0 \mathrm{mg} / \mathrm{kg}$ and $5.6 \mathrm{mg} / \mathrm{kg}$ produced typical ratedependent effects in both components for P585, while all doses of morphine produced rate-dependent effects in both components for P582.

\section{DISCUSSION}

The FI 5-min schedule produced behavior that was typical of such schedules (Ferster \& Skinner, 1957). That is, a period of no responding was followed by a gradual increase in responding until the reinforcer was delivered. Adding continuous clock stimuli to the FI 5-min baseline resulted in responding beginning later in the interval and with a much sharper scalloped pattern as indicated by the higher index of curvature values. Overall response rates were lower during the clocked FI components as well. This type of responding may represent a type of temporal discrimination. In the present study, the index of curvature is a measure of this type of discrimination, with higher 
indexes indicating better temporal discrimination. The differences in the pattern of responding suggest that the addition of clock stimuli enhanced the birds' temporal discrimination.

The effects of d-amphetamine and morphine on the index of curvature varied from no effect to a decrease indicating responding occurring earlier in the interval. During both the FI and clocked FI components, the lower doses of both drugs had no effect on the index of curvature, while the higher doses usually resulted in decreases in the index of curvature, or to complete suppression of responding such that the index could not be calculated. This result replicates past studies' findings of the effects of drugs on FI performance (Laties \& Weiss, 1966 and Odum \& Schaal, 1999). Breaking the interval down into tenths allows one to determine how responding changed within the interval after drug administration. The main changes in responding during the tenths of the interval were earlier-interval responding at intermediate doses and suppression of responding at the highest doses, i.e., a typical rate-dependent effect. This effect occurred for both d-amphetamine and morphine and was more pronounced during the FI component. Again, these results replicate the previous findings of Laties and Weiss (1966), Odum and Schaal (1999) and Palya and Bevins (1990). The main difference between these studies and the present one concerns the continuous clocked FI performance.

When clock stimuli have been added to FI schedules in past studies, the usual result is no effect of drugs on the index of curvature during the clocked components and decreases in the index of curvature during the regular FI components (Laties \& Weiss, 1966; Odum \& Schaal, 1999). The major difference between the results of the present 
study and past studies is that decreases in the index of curvature at the higher doses of drug were obtained during the clocked FI component. The most important finding in the present study was the alteration in the distribution of pecking throughout the interval. This alteration was obtained in both the regular FI and clocked FI components.

It is likely that the difference in how the clock stimuli were presented in this and in previous studies was the important factor. With the continuous clock, the beginning of the interval was discriminated from the end as evidenced by low to no responding during the beginning of the interval as compared to the highest response rates produced at the end of the interval. Moment-to-moment discrimination was more difficult such that there was more responding during the middle of the interval than obtained under a discrete clock. This could explain the decreases obtained in the index of curvature during the clocked FIs. A discrete clock provides the subject with reliable information about the timing of reinforcement; it will occur only during the last stimulus in the sequence. This type of arrangement requires only that the subject attend to the last stimulus, and Odum and Schaal (1999) suggested that pigeons respond as if the FI starts when the last stimulus, not the first stimulus, is presented. With a continuous clock, this signal for the start of the interval is less clear. Even though the beginning and the end of the interval are highly discriminable, the difficulty of moment-to-moment discriminations within the interval requires the animal to rely more on temporal discrimination earlier in the interval. The effects of both drugs suggest that this temporal discrimination was disrupted under the continuously clocked FI schedule since they began responding earlier in the interval as indicated by the decreases in the index of curvature values. dAmphetamine and morphine tended to increase response rates under the FI component 
usually beginning in the first minute of the interval, whereas increases in rate under the clocked FI component usually did not begin until later with only a few exceptions. Odum et al. (1998) found that response rates were increased by morphine even in the first $30 \mathrm{~s}$ of the FI schedule. Such a robust effect was not obtained in the present study with the response rates under the clocked FI component, suggesting that stimulus control in the most extreme portion of the clocked FI may be as rigid as under the discrete clock.

The procedure used in this experiment attempted to help decide between two interpretations of the "FI-clock effect." The results support the idea that clock stimuli change the FI task so that "timing" the entire interval is unnecessary. The clock stimuli in the present study forced the subjects to time more of the interval and as such drugs disrupted behavior during the clocked components. The data suggest that the clock stimuli do supplement this discrimination as evidenced by the attenuated effects of drugs during the clocked FI compared to during the FI component.

\section{Experiment 2}

The second experiment was a comparison of the effects of d-amphetamine and morphine on behavior maintained by FI 5-min, response-dependent clocked FI 5-min, and response-independent or discrete clocked FI 5-min components of a multiple schedule. Drugs should alter the FI performance more than the discrete clocked FI performance as seen in previous studies (Laties \& Weiss, 1966 and Odum \& Schaal, 1999). Since the baseline performance under response-dependent clocked FI schedules was intermediate between conventional FI and discrete clocked FI schedules (Segal, 1962 and Kendall, 1972), drug effects on the behavior maintained by the response-dependent clocked FI should be between those under the FI and discrete clocked FI components. 
This effect presumes that the alteration of temporal discrimination is the behavioral mechanism behind the differing performance under FI schedules and that the different types of clocks supplement the pigeons' temporal discrimination to differing degrees.

\section{METHOD}

$\underline{\text { Subjects }}$

The subjects were four adult male White Carneau pigeons (Palmetto Pigeon Plant, Sumter, SC) with previous exposure to various schedules of food reinforcement (see below). After a period of two weeks of unrestricted access to mixed grain, the freefeeding weights of the pigeons were determined as the mean of the last 7 daily weights. The pigeons were then maintained at $70 \%$ of their free-feeding weight. They were housed in a temperature-controlled colony under a light:dark cycle of 12:12 hr with unrestricted access to water and digestive grit.

Apparatus

The apparatus was as described in Experiment 1.

\section{$\underline{\text { Procedure }}$}

Experimental sessions occurred approximately at the same time 6 - 7 days a week. Pigeons were initially trained to peck keys using an autoshaping procedure in which keys of different colors were presented $5 \mathrm{~s}$ prior to 4 -s presentations of the hopper. Pecks to the keys produced immediate access to grain. When the pigeons were pecking each key color reliably, the FI schedules were arranged. Initially, it was intended for the conventional FI schedule to alternate with a clocked FI schedule in which three colors (green, white, and red) were presented in succession but in unpredictable order from interval to interval. This procedure would have allowed each key color to occupy each 
temporal position in the FI while still producing signals for the passing of time. The idea was to provide stimulus changes correlated with the passage of time while equating the "value" of the clock stimuli. After several weeks on this schedule, however, it was apparent that the pigeons did not treat this "randomized-clock" procedure as a clock in the usual sense; pecking occurred sporadically throughout the interval. This procedure was abandoned and the more conventional clocked FI schedule was introduced.

A multiple FI FI clock schedule was in effect during pretraining. Pretraining consisted of gradually increasing the FI schedule from $1 \mathrm{~min}$ up to $5 \mathrm{~min}$. Reinforcement throughout consisted of 4-s access to mixed grain. The session began with the FI component and after food was delivered or a 3-min hold had expired, the FI clock schedule began. These components alternated strictly. After 10 intervals, 5 FI and 5 FI clock, the session ended. The keylight was lit amber and the houselight was on during the FI component. During the FI clock component, the keylight changed from green $\left(1^{\text {st }}\right.$ third, or $100 \mathrm{~s}$, of the interval) to white ( $2^{\text {nd }}$ third of the interval) to red (final third of the interval) with no pecks required to produce the color change during the first phase of training (approximately one month). The next and final phase consisted of the addition of a third component in which the clock stimuli were presented dependent on key pecking.

In the final phase, the pigeons pecked keys on a multiple FI 5-min, responsedependent clocked FI 5-min, and response-independent clocked FI 5-min schedule of food presentation with strictly alternating components separated by a 1-s blackout. After a 10-min blackout, the session started. Each component was presented 4 times and the duration of each session was approximately 70 minutes. If the pigeons did not peck 
within 3 min after the end of the 5-min interval, the component ended and the next component began after the 1-s blackout. As before, during the FI component, the keylight was lit amber and the houselight was on throughout the interval. During the response-dependent clocked FI component, the keylight was lit blue if no pecking occurred and the houselight was on throughout the interval. If pigeons pecked during the first third of the interval, the key color changed from blue to green for $0.5 \mathrm{~s}$ and then back to blue. If the pigeon pecked during the second third of the interval, the key color changed from blue to white for $0.5 \mathrm{~s}$ and then back to blue. Finally, if the pigeon pecked during the last third of the interval, the key color changed from blue to red for $0.5 \mathrm{~s}$ and then back to blue. If the pigeon pecked the key during that $0.5 \mathrm{~s}$ period, the clock stimulus timer reset so that it was possible for the birds to continuously produce the clock stimulus during the interval. Also as before, during the response-independent clocked FI component, the houselight was on throughout the interval and for the first third of the interval, the keylight was lit green, during the second third of the interval the keylight was lit white, and during the last third of the interval the keylight was lit red. No pecks were required for the key color change to occur in this component. The same color sequence (green, white, red) was used for both clock components of this experiment with the only difference being whether or not a peck was required before the stimuli were presented.

\section{Drug preparation and administration}

The drug preparation and administration was as described in Experiment 1. 


\section{$\underline{\text { Data analysis }}$}

Data analyses were conducted as in Experiment 1 with the following exceptions. Responses were collected in twelve 25-s bins corresponding to the twelfths of the interval. Separate bins were used to accumulate responses from the different types of FI schedule. Overall response rates as well as response rates within the different twelfths and thirds of the interval were calculated.

\section{RESULTS}

\section{$\underline{\text { d-Amphetamine }}$}

The effects of d-amphetamine on the mean index of curvature (+/- 1 s.d.) are depicted in the left panels of Figure 8 for birds P597, P425, P829, and Pa30. The filled circles represent the index across all determinations under the FI components, the open boxes represent the index under the response-dependent clocked FI components, and the filled diamonds represent the index under the clocked FI components. The index of curvature was not calculated or plotted unless at least 20 pecks occurred in each component for the entire session. For all birds, the control value of the index of curvature was higher in the discrete clocked FI component, while there was no difference in the index values in the other 2 components. There was no effect of saline in any component for any bird. There were few clear effects of d-amphetamine on this measure of behavior. In the FI component, the only effect was a decrease seen in 2 birds, P829 and Pa30, starting at $1.0 \mathrm{mg} / \mathrm{kg}$ d-amphetamine and continuing through $5.6 \mathrm{mg} / \mathrm{kg} \mathrm{d}$ amphetamine. In both the response-dependent clocked FI and the discrete clocked FI components, the index of curvature was largely unaffected by d-amphetamine. This conclusion is supported by the percent of baseline index graphs as well. 

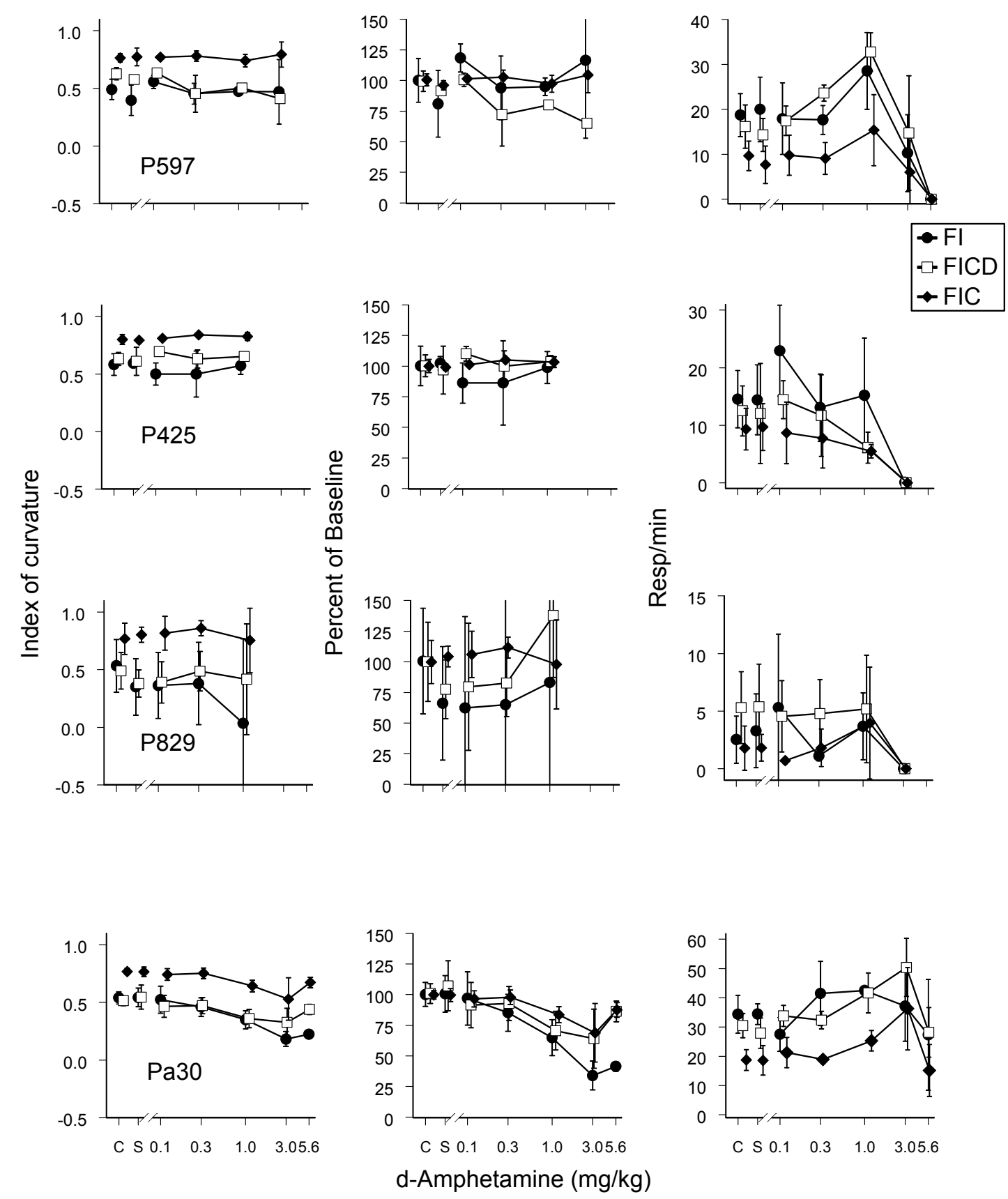

Figure 8. Effects of d-amphetamine on the index of curvature (left column), percent of baseline index of curvature (middle), and rates of key pecking (right column) calculated for the FI 5-min, response-dependent clocked FI 5-min, and response-independent clocked FI 5-min components of the multiple schedule for each pigeon (rows). Unconnected points show mean rates for all control sessions (C) and determinations of saline (S). Lines connect points showing mean rates for determinations of damphetamine and vertical bars represent one standard deviation above and below means. 
Figure 8 displays the effects of $d$-amphetamine on mean overall response rate $(+/-$ 1 s.d.). The control response rates followed a general trend with the lowest rates in the discrete clocked FI component, intermediate rates in the response-dependent clocked FI component, and the highest rates in the regular FI component except for P829 where response rates were the highest during the response-dependent clocked FI component. Again, saline had no effect on response rates in any component. For birds 597 and Pa30, there was an increase in the response rate under moderate doses of d-amphetamine in all components with the highest increase in response rate seen at the dose of $1.0 \mathrm{mg} / \mathrm{kg} \mathrm{d}$ amphetamine in the response-dependent clocked FI component for P597 and at $3.0 \mathrm{mg} / \mathrm{kg}$ in the response-dependent clocked FI and discrete clocked FI components for Pa30. For bird 425, an increase in response rate occurred in the FI component for $0.1 \mathrm{mg} / \mathrm{kg} \mathrm{d}$ amphetamine and complete responding was suppressed in all components at the dose of $3.0 \mathrm{mg} / \mathrm{kg} \mathrm{d}$-amphetamine. There was no effect of d-amphetamine on response rate for bird 829 until the $3.0 \mathrm{mg} / \mathrm{kg}$ dose at which point there was complete suppression of responding.

Indices of curvature (left panels) and overall response rate (right panels) generated for the first and last determination of each dose are represented in Figure 9. The open symbols represent the first determination, while the filled symbols represent the last determination. The circles represent the behavior under the FI components, the boxes represent the behavior under the response-dependent FI components, and the triangles represent the behavior under the discrete clocked FI components. There were few absolute differences in the index and response rate for the different determinations of d-amphetamine. Most of these differences were within the standard deviation of the 

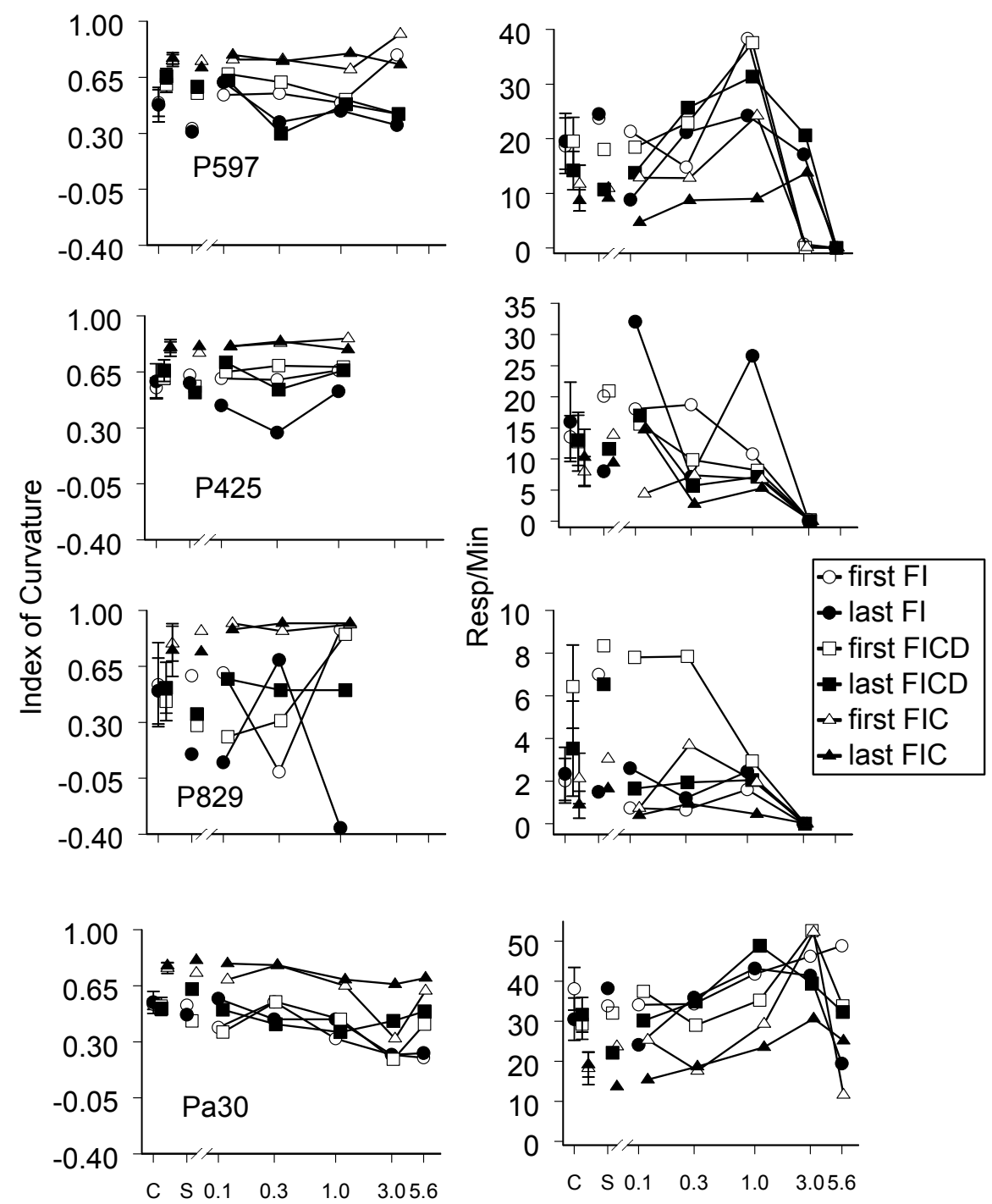

d-Amphetamine $(\mathrm{mg} / \mathrm{kg})$

Figure 9. Effects of the first and last determinations of d-amphetamine on the index of curvature (left column), and rates of key pecking (right column) calculated for the FI 5min, response-dependent clocked FI 5-min, and response-independent clocked FI 5-min components of the multiple schedule for each pigeon (rows). Unconnected points show mean rates for all control sessions $(\mathrm{C})$ and determinations of saline $(\mathrm{S})$. 
control points. In some cases, there were baseline shifts, meaning that over the course of the experiment the birds' response rate decreased. For example, P597's and P829's response rates in the clocked components slightly decreased. This baseline shift also occurred for Pa30 during the regular FI component. Any differences between the drug determinations in these components should be weighed against these shifts in order to see if a real difference occurred. For the index of curvature, the only consistent difference between the administrations of d-amphetamine were in the FI component for P425. In this case the index was higher after the first administration as opposed to the last, indicating, if anything, sensitization. There were more differences between response rate. The main consistencies were with P597 and P829 where the first determination of damphetamine doses produced higher rates than the last determination during the FI component and for P829 also during the response-independent clocked FI component. While other differences existed, none were consistent at all doses on the dose-effect curves. There were also a few differences between the first and last determinations of saline. However, most of these differences were in the range of control values such that there was no importance in the absolute differences that resulted from the saline administrations. A few of the differences after drug administrations reflected, in part, a shift in baseline as indicated by the control points.

The next 4 figures show response rate (responses/min) as a function of dose separated into thirds of the interval under each component. The thirds correspond to the segments of the clocked FI components associated with different stimuli. Under control sessions for all birds, response rate increased with increasing third of the interval in all FI components, except during the discrete clocked FI, where responding only occurred 
during the last third of the interval. Response rates during the first and second thirds of the interval were highest in the FI component, followed by the response-dependent clocked FI component, and no responses occurred in the discrete clocked FI component. Response rates during the last third of the interval were similar in all components, with slightly lower response rates in the discrete clocked FI component for most birds. There was no effect of saline on any response rate.

For P597 (Figure 10), during the first third of the interval there was no effect of damphetamine on response rate during the FI or clocked FI components. However, there was an increase in response rates at the doses of $1.0 \mathrm{mg} / \mathrm{kg}$ and $3.0 \mathrm{mg} / \mathrm{kg} \mathrm{d}$-amphetamine during the response-dependent clocked FI component. $5.6 \mathrm{mg} / \mathrm{kg}$ completely suppressed responding during the second third of the interval in the FI component; otherwise there was no effect. During the response-dependent clocked FI component, response rate was increased at $0.3 \mathrm{mg} / \mathrm{kg}$ and $1.0 \mathrm{mg} / \mathrm{kg}$ and completely suppressed at $5.6 \mathrm{mg} / \mathrm{kg}$. There was no effect of d-amphetamine on response rate in the discrete clocked FI component. For the last third of the interval in each component, there was an increase in responding at the dose of $1.0 \mathrm{mg} / \mathrm{kg} \mathrm{d}$-amphetamine and complete suppression of responding at 5.6 $\mathrm{mg} / \mathrm{kg} \mathrm{d}$-amphetamine. No reliable effect was obtained during the first third of the interval for any of the FI components, although rates were increased after $1.0 \mathrm{mg} / \mathrm{kg}$ during one of the determinations for P425 (Figure 11) and P829 (Figure 12). Throughout the second and final thirds of the interval, $3.0 \mathrm{mg} / \mathrm{kg}$ complete suppressed responding; otherwise there was no consistent effect of d-amphetamine.

An increase in response rate at the higher doses during the FI and responsedependent FI components occurred during the first third of the interval for Pa30 (Figure 

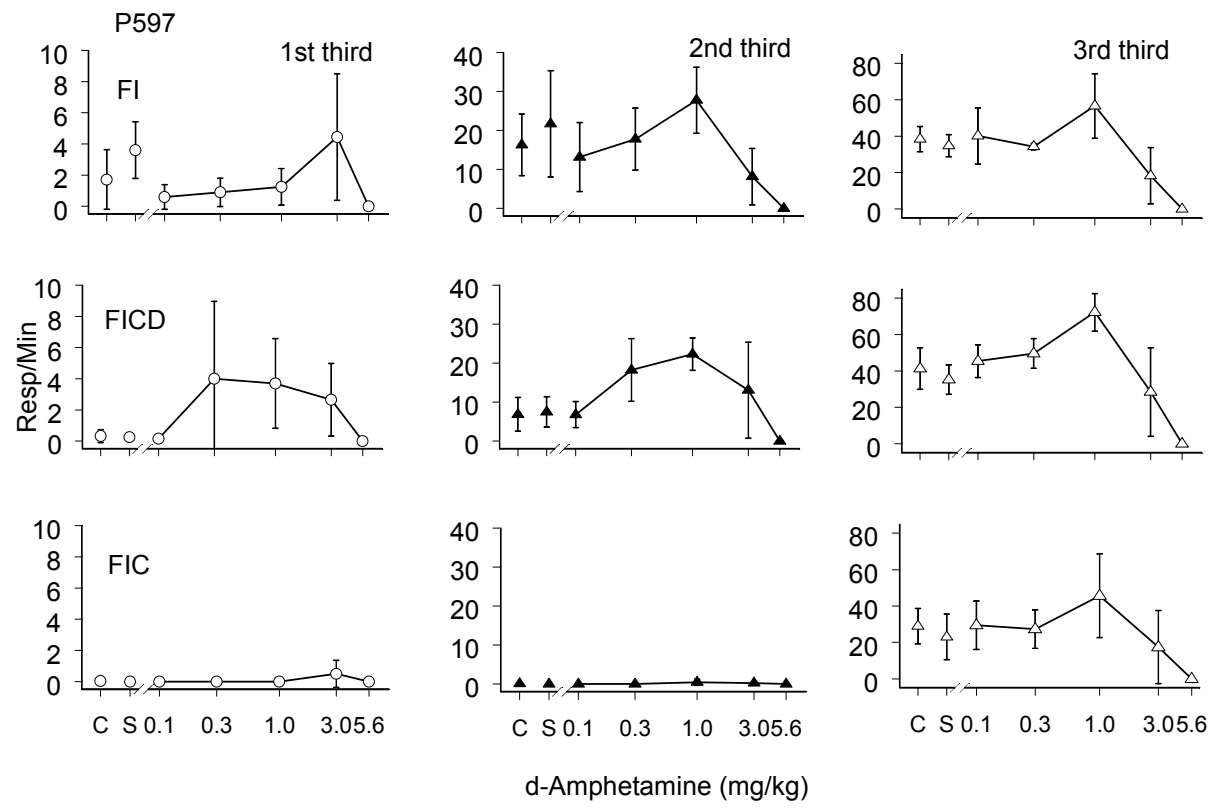

Figure 10. Responses/min plotted as a function of d-amphetamine dose for P597. Rows represent each component of the multiple FI 5-min, response-dependent FI 5-min, and response-independent FI 5-min schedule. Columns represent successive thirds of the interval. Unconnected points show mean rates for all control sessions (C) and determinations of saline (S). Lines connect points showing mean rates for determinations of d-amphetamine and vertical bars represent one standard deviation above and below means. 

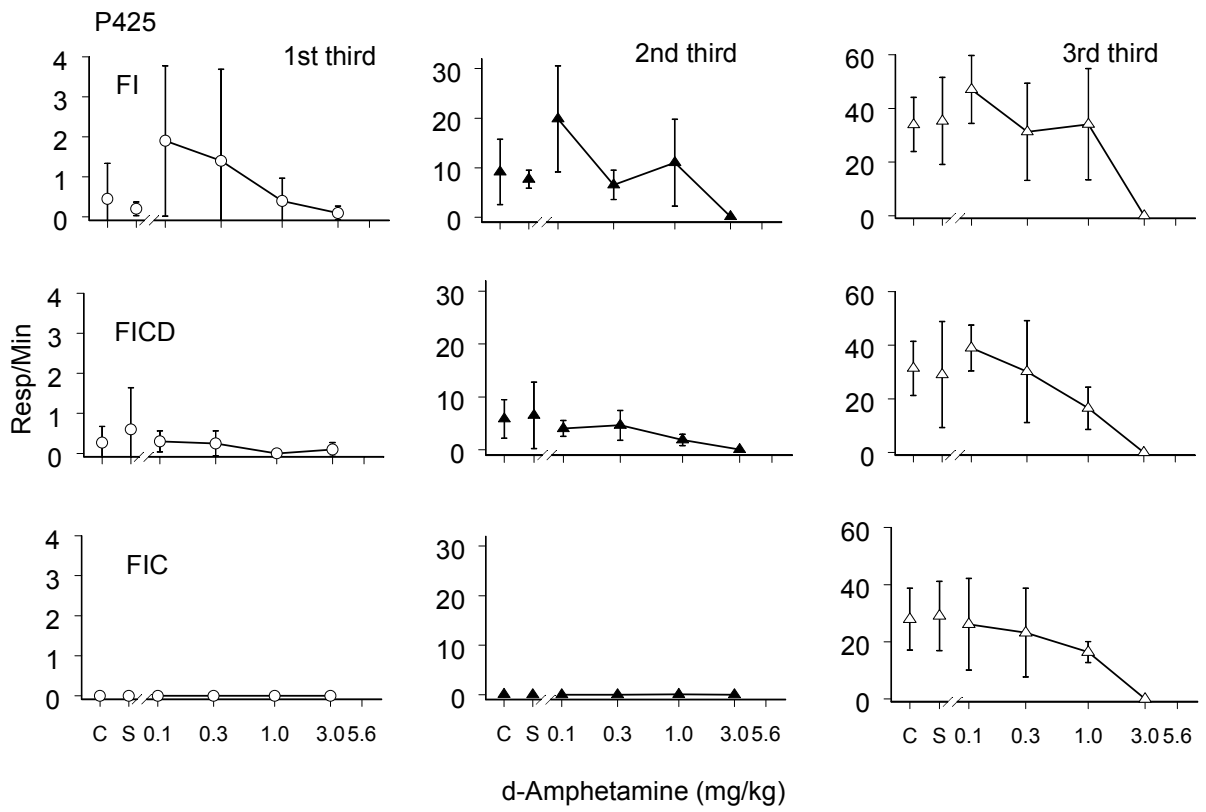

Figure 11. Responses/min plotted as a function of d-amphetamine dose for P425. Rows represent each component of the multiple FI 5-min, response-dependent FI 5-min, and response-independent FI 5-min schedule. Columns represent successive thirds of the interval. Unconnected points show mean rates for all control sessions (C) and determinations of saline $(\mathrm{S})$. Lines connect points showing mean rates for determinations of d-amphetamine and vertical bars represent one standard deviation above and below means. 

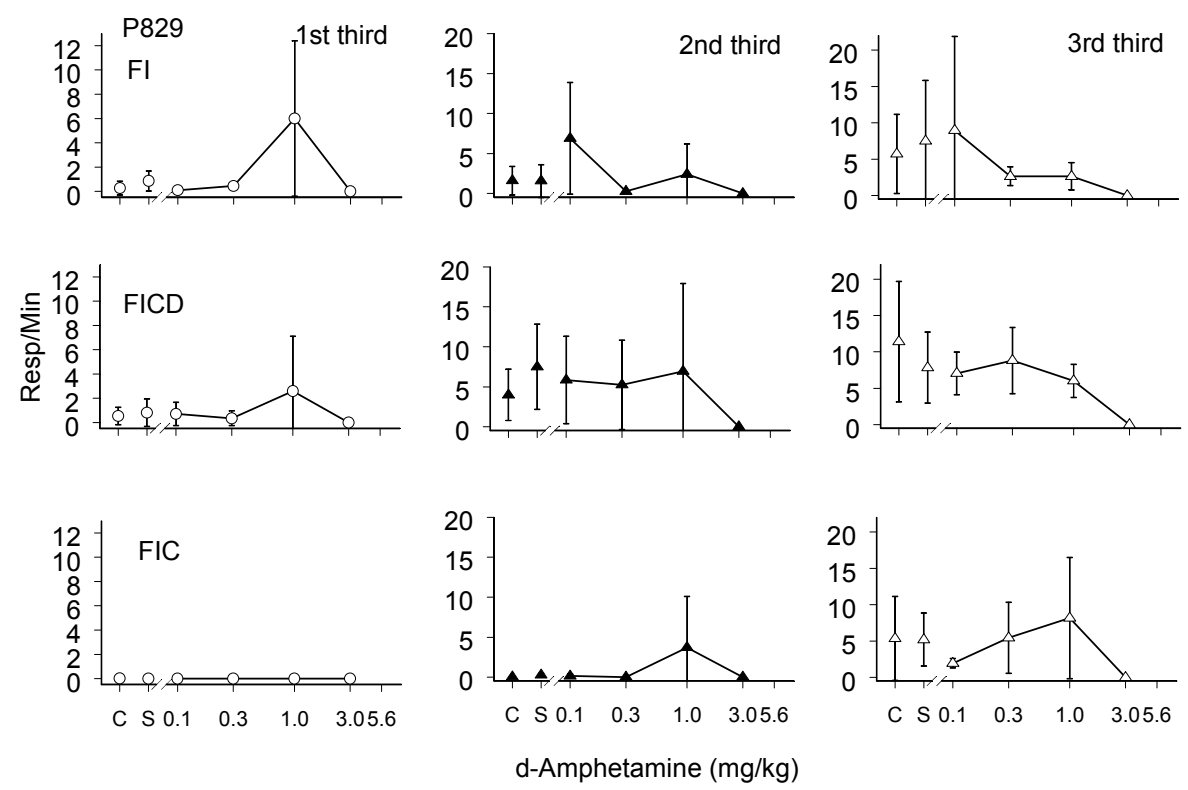

Figure 12. Responses/min plotted as a function of d-amphetamine dose for P829. Rows represent each component of the multiple FI 5-min, response-dependent FI 5-min, and response-independent FI 5-min schedule. Columns represent successive thirds of the interval. Unconnected points show mean rates for all control sessions (C) and determinations of saline $(\mathrm{S})$. Lines connect points showing mean rates for determinations of d-amphetamine and vertical bars represent one standard deviation above and below means. 

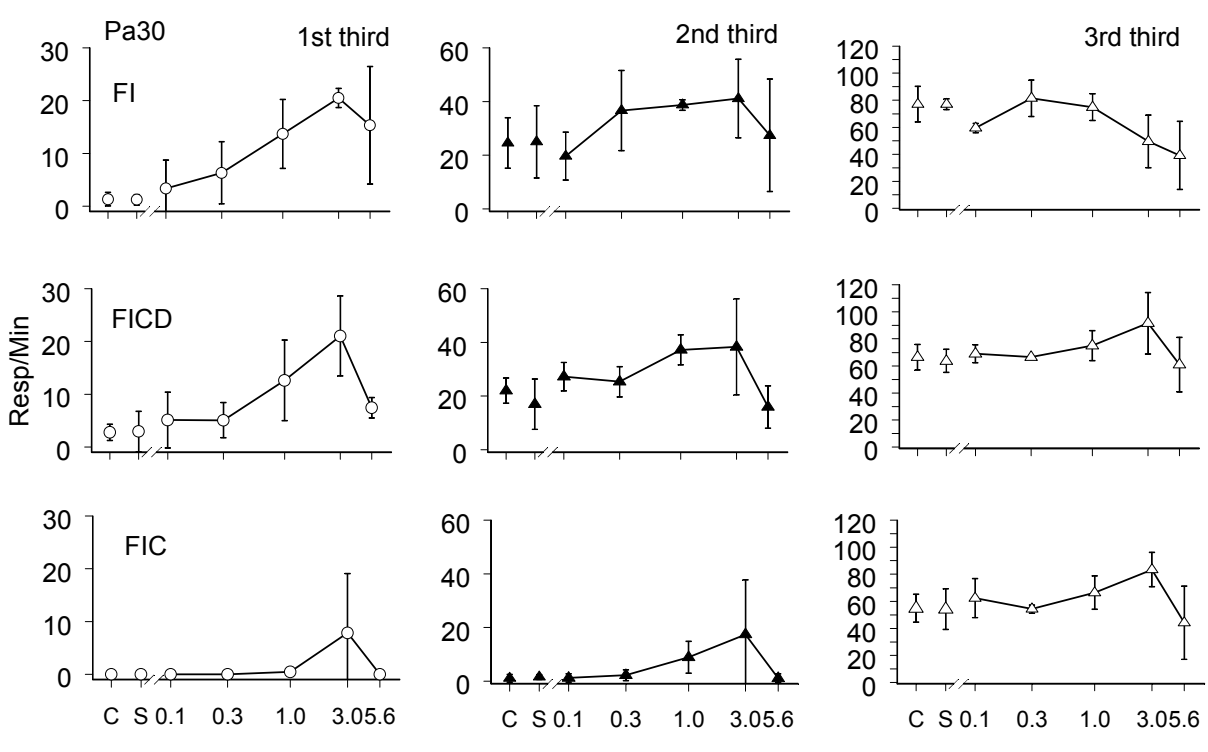

d-Amphetamine $(\mathrm{mg} / \mathrm{kg})$

Figure 13. Responses/min plotted as a function of d-amphetamine dose for Pa30. Rows represent each component of the multiple FI 5-min, response-dependent FI 5-min, and response-independent FI 5-min schedule. Columns represent successive thirds of the interval. Unconnected points show mean rates for all control sessions (C) and determinations of saline $(\mathrm{S})$. Lines connect points showing mean rates for determinations of d-amphetamine and vertical bars represent one standard deviation above and below means. 
13). d-Amphetamine had no effect on behavior during the discrete clocked FI

component. The single effect during the second third of the interval was an increase in response rate at the dose of $1.0 \mathrm{mg} / \mathrm{kg}$ in all FI components. During the final third of the interval, there was a decrease in response rate during the FI component at $0.1 \mathrm{mg} / \mathrm{kg}$ and at $3.0 \mathrm{mg} / \mathrm{kg}$ during the discrete clocked FI component.

Morphine

The effects of morphine on the index of curvature are depicted in the left and middle panels of Figure 14. The index of curvature was not calculated or plotted unless at least 20 pecks occurred in each component. Under baseline conditions, the discrete clocked FI component produced the highest index of curvature and the FI and responsedependent clocked FI components produced similar indices of curvature for all birds. There was no effect of saline in any component. In general, there was a dose-dependent decrease in the index of curvature during the FI component for three of the four birds and decreases in the index of curvature during the response-dependent clocked FI and discrete clocked FI component for three of the four birds at all doses of morphine. The main exception to all of these cases was bird P829. This bird only responded enough to calculate the index of curvature during the dose of $1.0 \mathrm{mg} / \mathrm{kg}$ morphine and there was no effect on this measure of behavior.

The effects of morphine on overall mean response rate can be seen in the right panels of Figure 14. In general, response rates were higher under the FI component, followed by the response-dependent clocked FI component, and the discrete clocked FI component produced the lowest rates of responding. There was no effect of saline on response rates for any of the birds. Low doses of morphine increased response rate for 

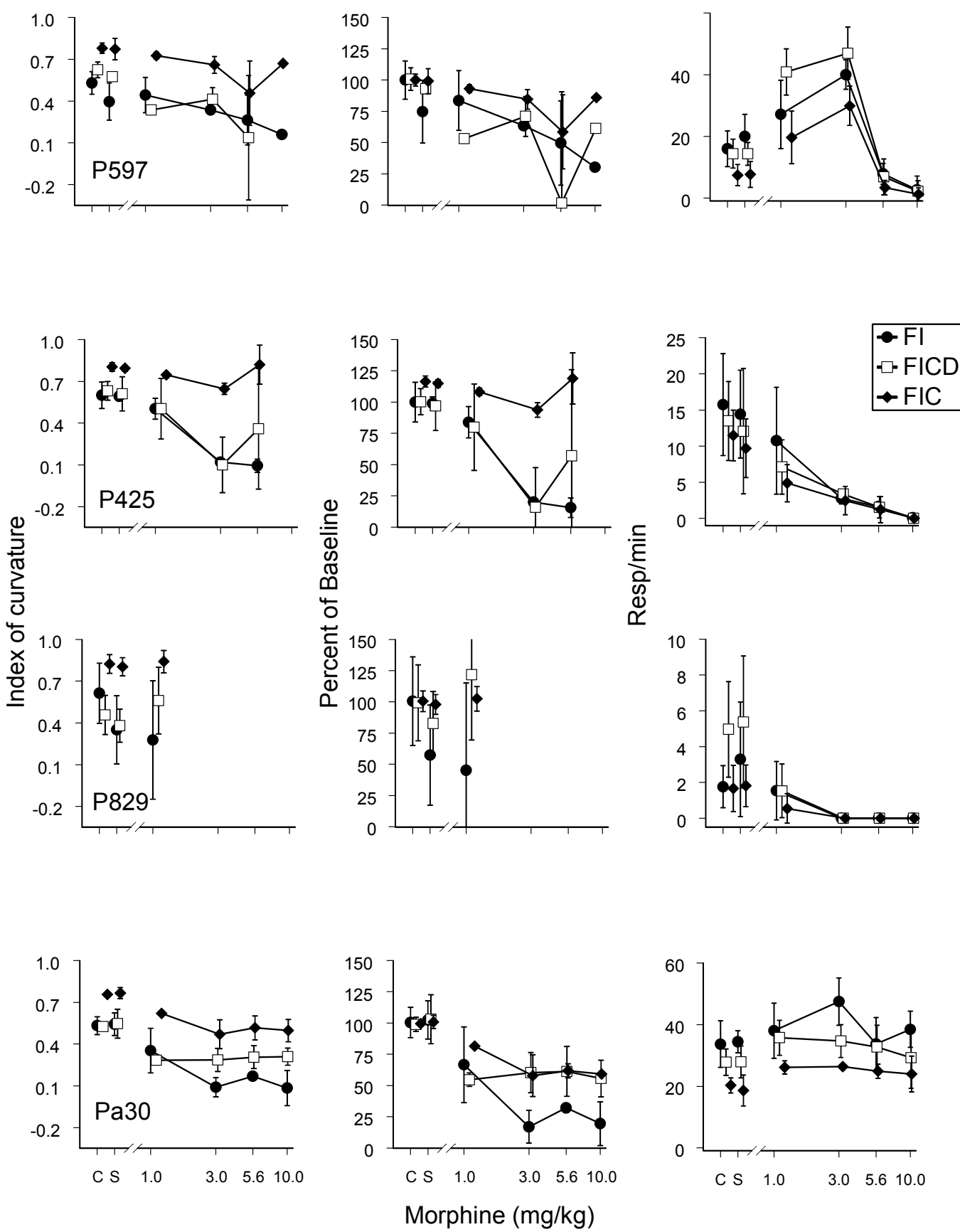

Figure 14. Effects of morphine on the index of curvature (left column), percent of baseline index of curvature (middle), and rates of key pecking (right column) calculated for the FI 5-min, response-dependent clocked FI 5-min, and response-independent clocked FI 5-min components of the multiple schedule for each pigeon (rows). Unconnected points show mean rates for all control sessions (C) and determinations of saline (S). Lines connect points showing mean rates for determinations of morphine and vertical bars represent one standard deviation above and below means. 

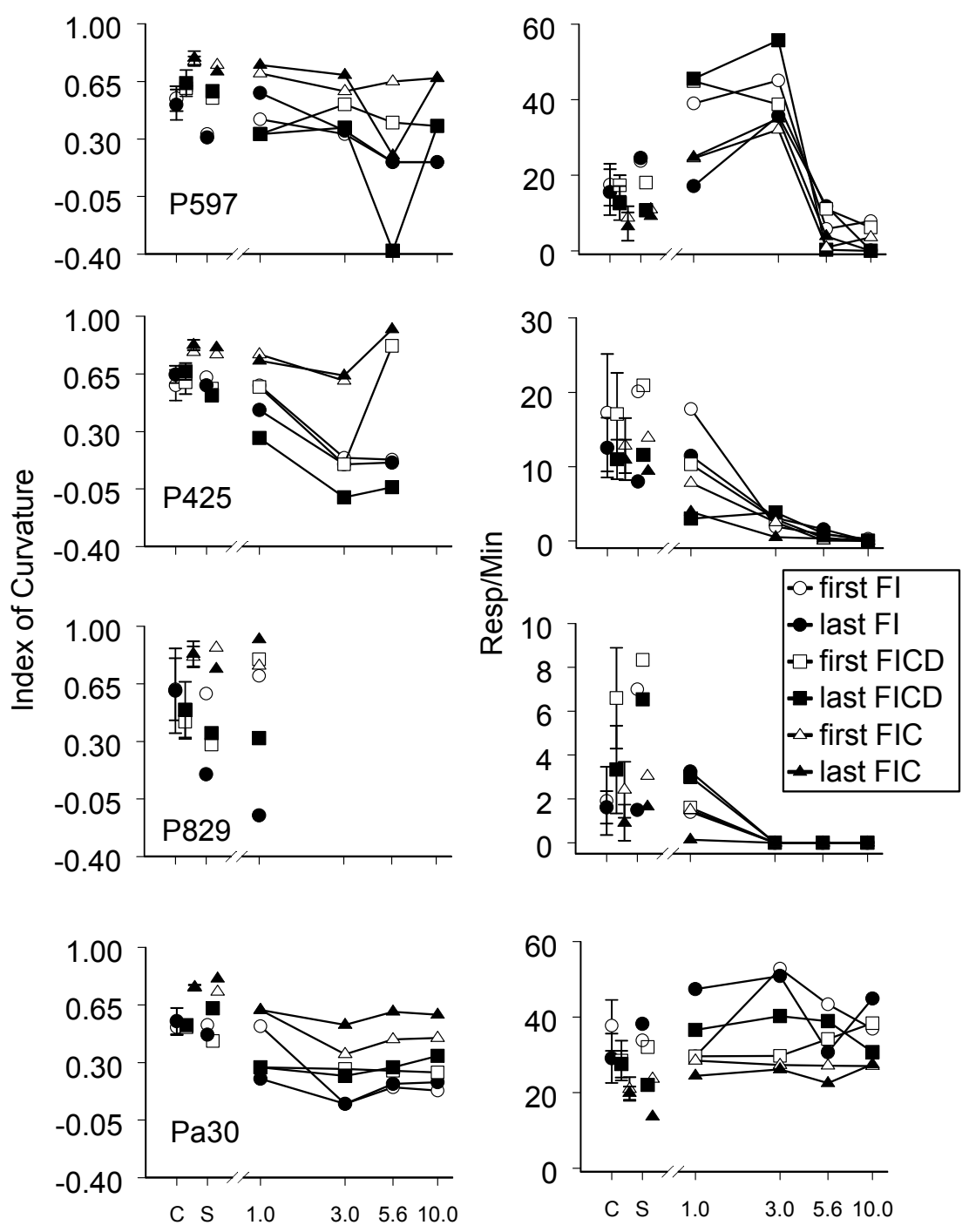

Morphine (mg/kg)

Figure 15. Effects of the first and last determinations of morphine on the index of curvature (left column), and rates of key pecking (right column) calculated for the FI 5min, response-dependent clocked FI 5-min, and response-independent clocked FI 5-min components of the multiple schedule for each pigeon (rows). Unconnected points show mean rates for all control sessions (C) and determinations of saline (S). 
P597, while higher does decreased response rate in all FI components. There was a dosedependent decrease in P425's response rate for all FI components. For bird P829, 1.0 $\mathrm{mg} / \mathrm{kg}$ morphine reduced the response rate in the clocked components and completely suppressed responding at all other doses. Finally, there was an increase in the response rate for Pa30 during the FI component at $3.0 \mathrm{mg} / \mathrm{kg}$ and there was a slight increase in response rate during the clocked components at the lower doses of morphine.

Figure 15 shows the indices of curvature (left panels) and overall response rate (right panels) generated for the first and last determination of each dose. Most of the comparisons between the first and last determination of morphine doses were similar. P829's data may be somewhat misleading in that it appears there are extreme differences between the determinations. This bird had very low response rates and as such even small differences in response rate can lead to big differences in the index of curvature. There were only 2 instances when the entire dose effect curve was shifted for the index of curvature with one case showing sensitization and the other tolerance. The index of curvature was higher after the first administration of doses of morphine during the response-dependent clocked FI component for P425 indicating sensitization. The index was higher after the last administration during the response-independent clocked FI component for Pa30, indicating tolerance. The only shift observed for response rate occurred during the response-dependent clocked FI component for Pa30 with the last determination of the doses of morphine producing higher response rates than the first determinations. There were also a few differences between the first and last determinations of saline and most of these occurred in the response rates. Most of these 

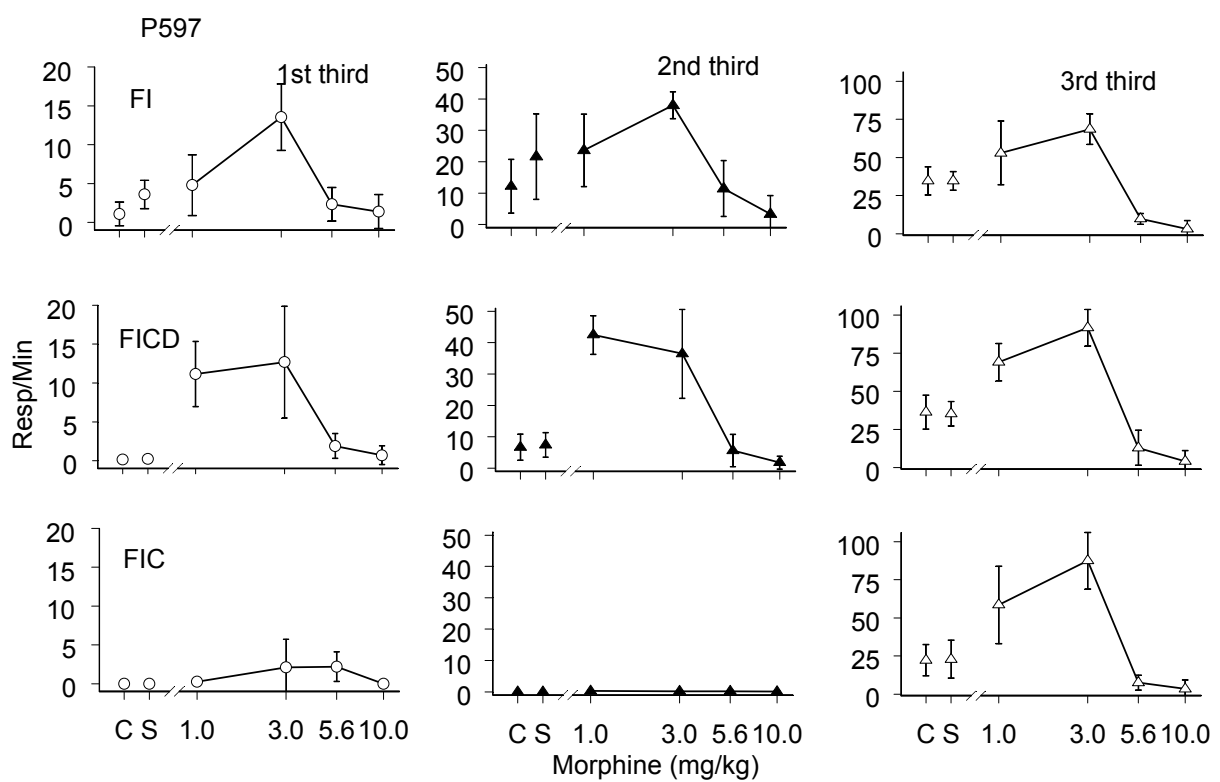

Figure 16. Responses/min plotted as a function of morphine dose for P597. Rows represent each component of the multiple FI 5-min, response-dependent FI 5-min, and response-independent FI 5-min schedule. Columns represent successive thirds of the interval. Unconnected points show mean rates for all control sessions (C) and determinations of saline (S). Lines connect points showing mean rates for determinations of d-amphetamine and vertical bars represent one standard deviation above and below means. 

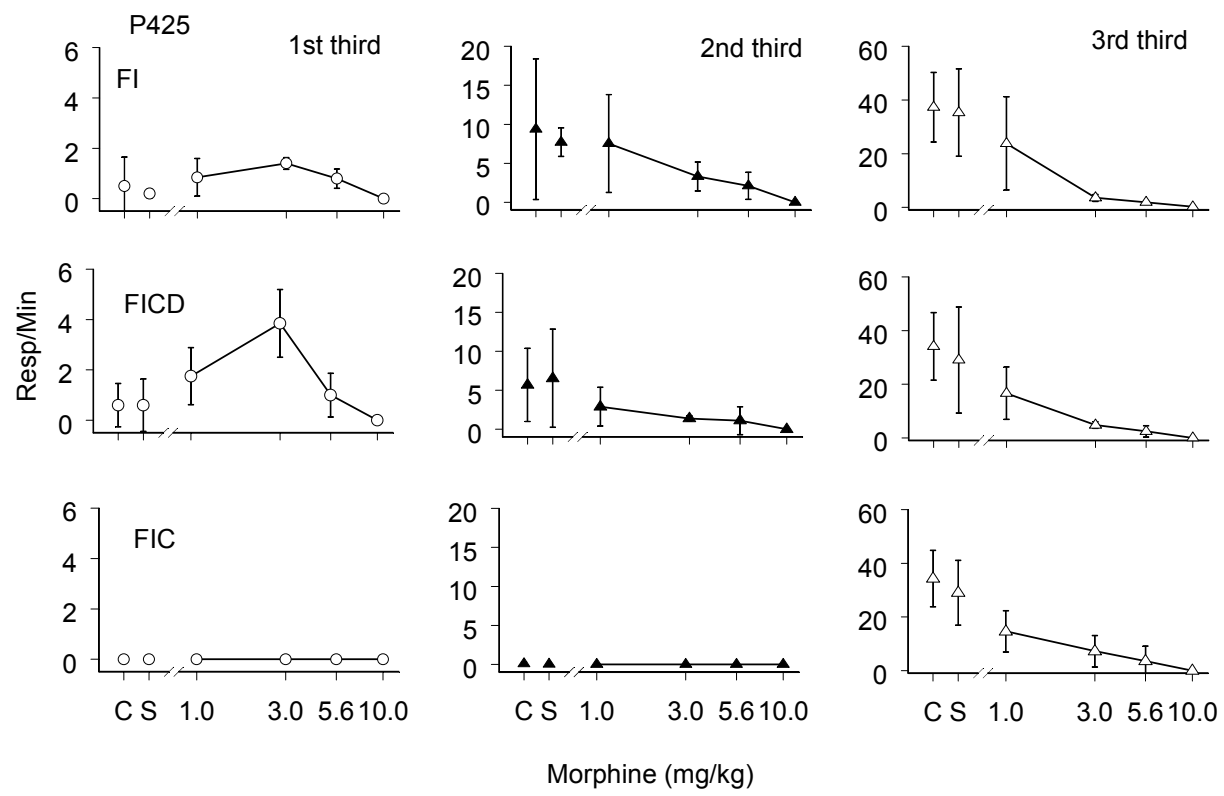

Figure 17. Responses/min plotted as a function of morphine dose for P425. Rows represent each component of the multiple FI 5-min, response-dependent FI 5-min, and response-independent FI 5-min schedule. Columns represent successive thirds of the interval. Unconnected points show mean rates for all control sessions (C) and determinations of saline (S). Lines connect points showing mean rates for determinations of d-amphetamine and vertical bars represent one standard deviation above and below means. 
differences were in the range of control values indicating that the difference can be accounted for in the variance of the baseline behavior.

The next 4 figures show response rate (responses/min) as a function of dose separated into thirds of the interval under each component. Under control sessions for all birds, response rate increased with increasing third of the interval in all FI components, except during the discrete clocked FI, where responding only occurred during the last third of the interval. Response rates during the first and second thirds of the interval were highest in the FI component, followed by the response-dependent clocked FI component, and no responses occurred in the discrete clocked FI component. Response rates during the last third of the interval were similar in all components, with slightly lower response rates in the discrete clocked FI component for most birds. There was no effect of saline.

For P597 (Figure 16) during the first and second thirds of the interval, there was an increase in response rate at $3.0 \mathrm{mg} / \mathrm{kg}$ during the FI component and an increase in response rate at $1.0 \mathrm{mg} / \mathrm{kg}$ and $3.0 \mathrm{mg} / \mathrm{kg}$ during the response-dependent clocked FI component. There was no effect of morphine on response rate during the discrete clocked FI component. During the final third of the interval, the lower doses produced an increase in response rate, while the higher doses produced a decrease in response rate during all FI components.

The only effect of morphine on P425's responding during the first third of the interval was at the dose of $3.0 \mathrm{mg} / \mathrm{kg}$ during the response-dependent clocked FI component where the response rate was increased (Figure 17). During the second third of the interval, there was no effect of morphine on responding except complete suppression at $10.0 \mathrm{mg} / \mathrm{kg}$. During the final third of the interval, there is a dose- 

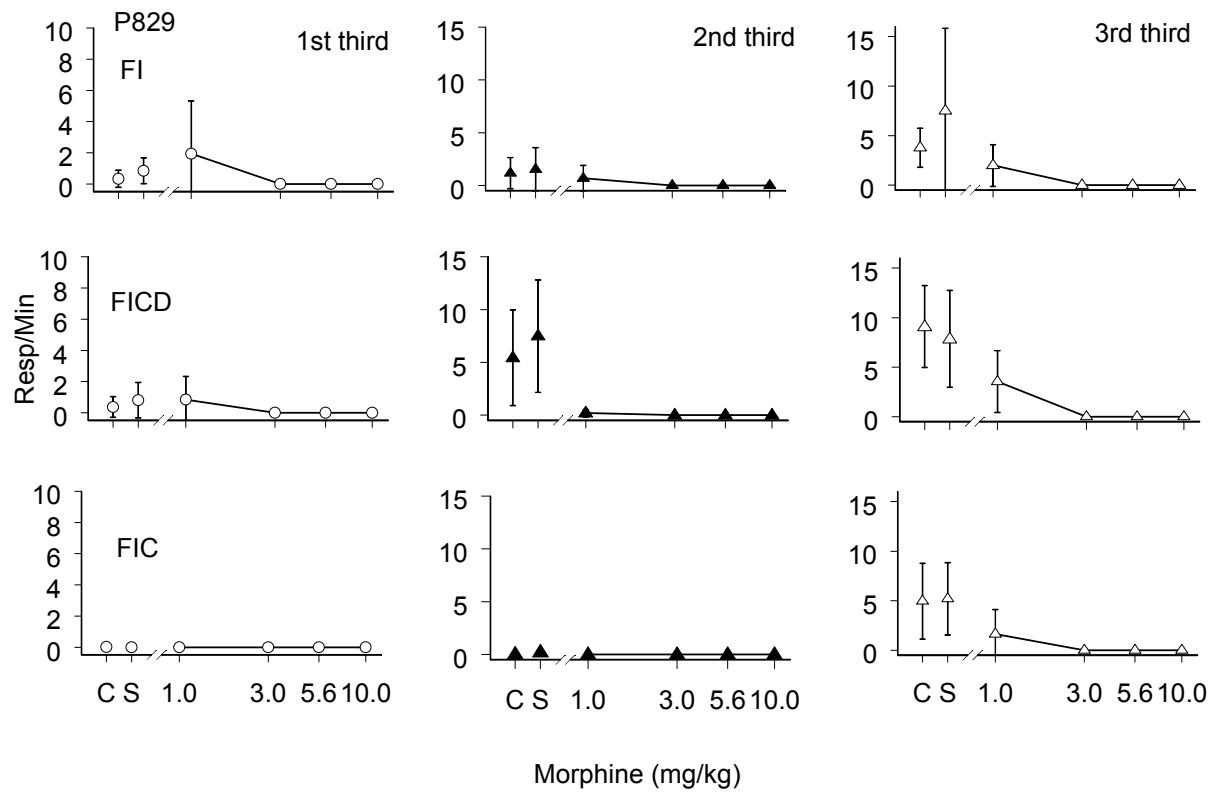

Figure 18. Responses/min plotted as a function of morphine dose for P829. Rows represent each component of the multiple FI 5-min, response-dependent FI 5-min, and response-independent FI 5-min schedule. Columns represent successive thirds of the interval. Unconnected points show mean rates for all control sessions (C) and determinations of saline (S). Lines connect points showing mean rates for determinations of d-amphetamine and vertical bars represent one standard deviation above and below means. 

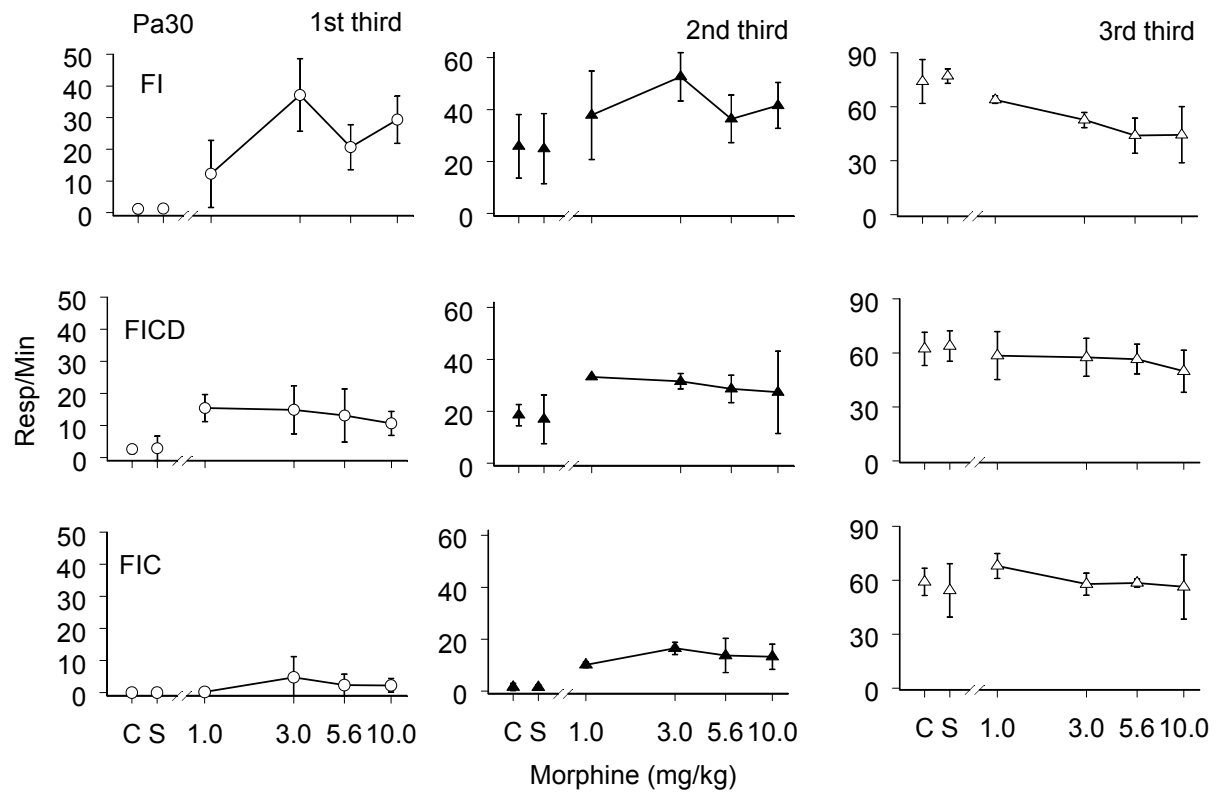

Figure 19. Responses/min plotted as a function of morphine dose for Pa30. Rows represent each component of the multiple FI 5-min, response-dependent FI 5-min, and response-independent FI 5-min schedule. Columns represent successive thirds of the interval. Unconnected points show mean rates for all control sessions (C) and determinations of saline (S). Lines connect points showing mean rates for determinations of d-amphetamine and vertical bars represent one standard deviation above and below means. 
dependent decrease in response rate for all FI components. There was no effect of morphine on P829's response rate (Figure 18) during the first third of the interval. 1.0 $\mathrm{mg} / \mathrm{kg}$ decreased response rate during the response-dependent clocked FI component in the second third of the interval. During the final third of the interval, complete suppression of responding occurred after the administration of $3.0 \mathrm{mg} / \mathrm{kg}$ and higher doses of morphine.

For Pa30 (Figure 19) there was a increase in response rate during the first third of the interval at all morphine doses during the FI and response-dependent clocked FI components. There was no drug effect during the discrete clocked FI component. During the second third of the interval, there was an increase in response rate during the FI component at $3.0 \mathrm{mg} / \mathrm{kg}$. All doses of morphine except $10.0 \mathrm{mg} / \mathrm{kg}$ produced increases in response rate during the response-dependent clocked FI component. In the final third of the interval, there was a dose-dependent decrease in response rate during the FI component and no effect of morphine during the other components.

\section{DISCUSSION}

The FI 5-min baseline component produced the typical scalloped pattern of responding. When response-dependent clock stimuli were added to this baseline, the birds started responding later in the interval with a much sharper scalloped pattern of behavior. The pigeons started responding even later in the interval during the component with response-independent clock stimuli. As a result, the indices of curvature were highest in the discrete clocked FI component, followed by the response-dependent clock FI component, and were lowest in the regular FI component. Response rates were also lower during both of the clocked FI components. Overall, d-amphetamine had few 
systematic effects on the index of curvature. The main effect was a decrease during the FI component in two of the four birds, an effect that replicates results of Laties and Weiss (1966). d-Amphetamine increased overall response rates during each FI component at moderate doses for two of the birds, and suppressed responding at the higher doses in all birds. Morphine either decreased or did not alter the index of curvature in all FI components. Response rates were increased at low doses in two of four birds and were decreased at the highest doses for all birds. Drugs tended to have more of an effect on behavior during the FI component than during the clocked components. This is true of the drug effects between the different clocked components as well, with behavior in the response-dependent clocked component being intermediate between the regular FI and the response-independent clocked components.

The differences obtained in baseline performances across components are consistent with previous studies (Segal, 1962; Laties \& Weiss, 1966; \& Odum \& Schaal, 1999). Segal (1962) found that post-reinforcement pauses were shorter in the conventional FI, longer in the response-independent clocked FI, and intermediate in the response-dependent clocked FI. Response rates followed a complementary pattern, with the response-dependent clocked FI generating rates that were intermediate to the conventional FI and the response-independent clocked FI. As suggested by Palya and Bevins (1990) and Odum and Schaal (1999), the differences between the different clocked FI and conventional FI schedules could be due to either the time-signaling or the contingency-signaling function of the clock stimuli. That is, either clock stimuli improve a temporal discrimination while maintaining control by the overall fixed interval, or they break the interval into segments with vastly different functions, and in so 
doing eliminate control by the overall fixed interval. The present experiments do not allow a determination of which is the better account, because it is possible that the continuous clock stimuli of Experiment 1 and the response-dependent clock stimuli of Experiment 2 required some level of temporal discrimination by being less effective signals. The progressive changes in the continuous clock stimuli were difficult to discriminate and the response-dependent clock stimuli were only presented briefly, so they did not signal progress through the interval as clearly as did the responseindependent clock stimuli. To the extent that behavior in these clocked components was more sensitive to alteration by the drugs than behavior in the more conventional clocked FI schedule, one can conclude that the drugs disrupted the temporal pattern of behavior when some level of temporal discrimination was required, and were less likely to do so when the need for temporal discrimination early in the interval was eliminated.

Alterations in the patterns of behavior did not occur as reliably in the present study as they did in prior studies (Laties \& Weiss, 1966; Odum \& Schaal, 1999) and the usual rate-dependent effects of these drugs were not as robust as in previous studies (Dews, 1958; Barrett, 1974; McMillan \& Healy, 1976; and McAuley \& Leslie, 1986). It is not clear why the present results differed from previous ones. It may be that the addition of the response-dependent clock FI component, which resulted in several earlyinterval key pecks, made behavior in the response-independent clocked FI component more sensitive to alteration. The clock stimuli were the same in both conditions (green, white, and red), which might have contributed to some carry-over effect that allowed for early-interval pecks during the response-independent clocked FI component. It may be more important that the birds had exposure prior to the present experiment to conditions 
in which each of these clock stimuli was paired with food (see Procedure). The goal of these conditions was to arrange sequences of three stimuli correlated with the passage of time without differentially correlating any of the stimuli with food (or with no food). As noted previously, this procedure did not produce the sort of clock-stimulus control typically observed in ordinary clocked FI schedules; pigeons pecked all the stimuli regardless of their position within the interval, presumably because each of the stimuli was occasionally paired with food. Despite the fact that the pigeons were then exposed to a fixed order of clock stimuli for many weeks prior to drug testing, it is possible that this prior experience with clock stimuli presented in mixed orders relative to food produced behavior that was sensitive to increases produced by the drugs.

The effects of d-amphetamine and morphine on behavior during the responsedependent clocked FI components were often intermediate between the regular FI and discrete clocked FI components. Adding clock stimuli to the conventional FI schedule could change the situation in several ways. One way is to make the situation qualitatively different so that the behavioral processes that control FI performance, such as temporal discrimination, are no longer effective when clock stimuli are present. The more likely explanation is that the clock stimuli influence the amount of or extent of control by the passage of time. The effects of drugs on the different FI components were similar, but occurred to a different degree in each of the components. This result may be an indication that more of the interval was being timed by the birds during the responsedependent FI relative to the response-independent FI component. If the birds were discriminating the interval in the response-dependent component as they were in the regular FI component, one would expect a few early pecks. However, when the bird 
pecked, stimuli indicating the approximate time in the interval were presented. The response-dependent clock stimuli may "put the brakes on" any tendency for response rates to be increased by drugs. During the discrete clocked FI component, the bird does not have to start discriminating time in the interval until the last stimulus is presented, so there is a lesser tendency for rates to be increased by drug. Of course, this interpretation of the current data is complicated by the fact that the typical effects of drugs on the conventional FI and clocked FI schedules did not occur as clearly as in previous studies.

\section{GENERAL DISCUSSION}

FI schedules of reinforcement were used in the present experiments for several reasons: the temporally organized behavior patterns generated by these schedules are sensitive to alteration by drugs, rate-dependent effects of drugs are easily detectable, and one may introduce time-correlated stimuli within intervals. It is commonly assumed that timing or temporal discrimination is an inherent requirement of FI schedules. To maximize reinforcement and minimize effort, temporal discrimination of the time in the interval is necessary. When stimuli that are correlated with the passage of the interval are added, temporal discrimination is either supplemented or becomes less necessary (Laties \& Weiss, 1966; Odum \& Schaal, 1999; Palya \& Bevins, 1990; Segal, 1962). While Laties and Weiss (1966) and Odum and Schaal (1999) found that drugs affected behavior generated by clocked FI and FI components differently, Odum and Schaal also found behavior during the last stimulus in the clock sequence was altered by morphine just as behavior during the conventional FI schedule was altered. They concluded that what was really being investigated was an FI 5-min schedule compared to an FI 75-s schedule preceded by a long inter-trial interval. It was as though the birds did not begin to 
discriminate time until the "start" of the final stimulus. Similarly, Palya and Bevins (1990) suggested that certain clock stimuli could be characterized as start signals. They assert that FI performance establishes a temporal gradient that inhibits early-interval responding and excites late-interval responding. The point at which one begins responding along this temporal gradient may be altered by adding clock stimuli such that the "start" signal is the last stimulus of the clocked FI. The main difference between these explanations is the time included in the temporal gradient. Odum and Schaal suggest that the birds do not start timing until the presentation of the last clock stimulus, which essentially shortens the FI value to the time contained in the last portion of the overall FI. Palya and Bevins suggest that the entire interval is timed but the birds are given a "start to respond" signal so that any early interval responding is suppressed by the absence of the last clock stimulus. Both of these explanations can account for the difference between drug effects on behavior generated by clocked FI and conventional FI schedules by the function of the "start" signal. For Odum and Schaal's explanation, the "start to discriminate time" signal is the last clock stimulus. Drugs may disrupt the temporal discrimination within that period of time but not outside of that signaled period. Palya and Bevins' "start to respond" signal occurs within the last clock stimulus, meaning that it signals the point in the gradient when the excitation of responding occurs. In this case, drugs may disrupt the initiation of responding within the period of time signaled by the last clock stimulus. Both of these would result in suppression of early-interval responding, but by different mechanisms.

The important difference between the present results and previous results on studies involving clocked FI schedules was that drugs did affect the behavior maintained 
under the clocked FI components similarly to the way behavior is affected by drugs under a regular FI schedule in that there was in increase in early-interval responding. Although the effects on the two types of components were not exactly the same, the drug effects on the behavior under the clocked FI components more closely approximated the drug effects on the behavior under the FI components than any previous study involving discrete clocked FI schedules (Laties \& Weiss, 1966; Odum \& Schaal, 1999). Even though these results were not as robust, they still suggest that the continuously clocked FI and response-dependent clocked FI procedures may be better ways of equating clocked FI schedules with FI schedules that have no stimuli correlated with the passage of time. That is to say, these clocked arrangements maintained the importance of temporal discrimination of the interval. A general conclusion, therefore, is that when temporal discrimination of a fixed interval is still required, even if to a lesser extent, then temporally organized behavior is sensitive to disorganization by these drugs.

A final, larger question is unanswered by ours and others data from FI and FI clock schedules; why do drugs alter the pattern of behavior on FI schedules as they do? A disruption of temporal discrimination alone does not account for the rate increases early in the interval, because such a disruption could as reasonably be indicated by a reduction in responding late in the interval. In studies with FI schedules, however, behavior near the ends of intervals is the most resistant to alteration by drugs. Church and Gibbon (1982) using a scalar expectancy theory (SET) model, suggest that the temporal gradient is shifted to the left due to an increase in the pacemaker rate. The pacemaker is a type of internal cue that the subject uses in temporal situations, which changes with the passage of time. This pacemaker can be reset at certain times, such as 
with the presentation of food, and can also be affected by other external events such as overall reinforcement rate. If there is a leftward shift in temporal discrimination, then the subject will respond as if more time has passed than actually has. This explanation does not take into account extremely early responding such as in the very beginning of the FI, whereas rate dependency describes this behavior change adequately.

Church and Gibbon (1982) go on to say that in timing situations, the subjects may not attend to the relevant aspects of the experiment. For example, in one of their experiments, the task was to respond based on the duration of a stimulus. If the subject did not attend to the duration of the stimulus, then responding was determined by other factors, such as level of motivation. Drugs may have their effects on behavior by disrupting attention to the temporal dimension of the FI stimulus, such that in the absence of attention, the rate of responding is determined by other factors. This point is supported by Odum and Schaal (2000). They trained pigeons to respond on an FI 1-min schedule with occasional temporal discrimination trials superimposed upon it. These discrimination trials consisted of interrupting the FI with a choice trial in which the side keys were lit different colors. If the interruption occurred a short time into the FI the bird was to choose one color and if the interruption occurred late in the FI the bird was to choose the other color. Pigeons learned this task, thus indicating their discrimination of the time since the start of the interval. Morphine disrupted the patterning of responding during the FI and also the overall accuracy of the temporal discrimination. This suggests that the underlying cause of the change in patterning produced by morphine was a failure of the pigeons to attend to the temporal aspect of the schedule stimuli. The concept of attention was discussed by Dinsmoor (1995). He relates attention to making observing 
responses. Within a discrimination, the stimuli that are conditioned reinforcers can maintain observing responses, while stimuli that are not correlated with reinforcement do not. In these cases, the stimuli not correlated with reinforcement become aversive. The different clock stimuli allow for this discrimination with the early stimuli being aversive, while the animals observe or attend to the later stimuli.

There are many determinants of FI schedule performance, some of which occur prior to the onset of the interval, such as stimulus conditions associated with the interval or the type of food reinforcement. The fact that food was just delivered prior to the onset of the present interval and the next food delivery is some time in the future may give the early portions of the interval aversive properties, which could lead to an inhibition of responding during the early part of the interval. The early portions of an FI schedule have been shown to possess aversive qualities. Brown and Flory (1972) allowed pigeons the opportunity to escape from stimuli associated with a fixed-interval by pecking a second "escape key." When the birds did escape, it was always after reinforcement during the early part of the interval and never right before reinforcement presentation or the later part of the interval. Richards and Rilling (1972) found that pigeons allowed the chance to attack another pigeon during an FI attacked right after food delivery. Effects such as these suggest that the early part of the FI is aversive. Drugs may have their effects by reducing that aversiveness allowing for responding because it is no longer inhibited by the aversiveness of the situation.

Following the early part of the FI, there is a point in time in the interval when things change. The upcoming food delivery is more likely and the aversive properties are outweighed by the excitation of responding. During the later portions of the interval, 
especially during the clocked intervals, the stimulus conditions are different which leads to a high probability of responding. When the temporal factors controlling behavior in the FI are reduced, then these other types of factors have more of an important role in determining FI-schedule performance. This type of effect occurred in Odum, Haworth, and Schaal (1998) and Schaal, Miller, and Odum (1995), where the effects of drugs were amplified when the pigeons were at a higher level of food deprivation. Thus, in the presence of drugs powerful stimuli may evoke responding in highly motivated animals irrespective of the time since the onset of the trial. 


\section{$\underline{\text { References }}$}

Antoniou, K. \& Kafetzopoulos, E. (1991). A comparative study of the behavioral effects of d-amphetamine and apomorphine in the rat. Pharmacology, Biochemistry, and Behavior, 39, 61-70.

Auge, R.J. (1977). Stimulus functions within a fixed-interval clock schedule: Reinforcement, punishment, and discriminative stimulus control. Animal Learning \& Behavior, 5, 117-123.

Baron, A. \& Leinenweber, A. (1994). Molecular and molar analyses of fixedinterval performance. Journal of the Experimental Analysis of Behavior, 61, 11-18.

Barrett, J. E. (1974). Conjunctive schedules of reinforcement I: Rate-dependent effects of pentobarbital and d-amphetamine. Journal of the Experimental Analysis of Behavior, 22, 561-573.

Bordi, F. \& Matthews, T. J. (1990). Effects of d-amphetamine, diazepam, and pentobarbital on the schedule-controlled pecking and locomotor activity of pigeons. Journal of the Experimental Analysis of Behavior, 53, 87-102.

Branch, M. N. (1984). Rate dependency, behavioral mechanisms, and behavioral pharmacology. Journal of the Experimental Analysis of Behavior, 42, 511-522.

Branch, M. N. (1993). Behavioral factors in drug tolerance. In J. P. Huston (Series Ed.) and F. van Haaren (Vol. Ed.), Methods in behavioral pharmacology: Vol. 10, Techniques in the behavioral and neural sciences (pp. 329-347). Amsterdam: Elsevier. 
Branch, M. N., \& Gollub, L. R. (1974). A detailed analysis of the effects of damphetamine on behavior under fixed-interval schedules. Journal of the Experimental Analysis of Behavior, 21, 519-539.

Branch, M. N., \& Schaal, D. W. (1990). The role of theory in behavioral pharmacology. In Thompson, T., Dews, P. B. \& Barrett, J. E. (Eds.) Advances in Behavioral Pharmacology, Vol. 6 (pp. 171-196). Orlando: Academic Press.

Brown, T. G. \& Flory, R. K. (1972). Schedule-induced escape from fixedinterval reinforcement. Journal of the Experimental Analysis of Behavior, 17, 395-403.

Church, R. M. (1984). Properties of an internal clock. In Gibbon, J. and Allen, L. (eds.), Timing and time perception (pp. 566-582). New York: New York Academy of Sciences.

Church, R. M. \& Gibbon, J. (1982). Temporal generalization. Journal of Experimental Psychology: Animal Behavior Processes, 8, 165-186.

Cohen, S. L. (1991). Effects of d-amphetamine on responding under secondorder schedules of reinforcement with paired and nonpaired brief stimuli. Journal of the Experimental Analysis of Behavior, 56, 289-302.

Cook, L. \& Kelleher, R. T. (1962). Drug effects on the behavior of animals. Annals of the New York Academy of Sciences, 96, 315-335.

Dews, P. B. (1958). Studies on behavior: IV. Stimulant actions of methamphetamine. Journal of Pharmacology and Experimental Therapuetics, 122, 137147. 
Dews, P. B., \& Wenger, G. R., (1977). Rate-dependency of the behavioral effects of amphetamine. In T. Thompson \& P. B. Dews (Eds.), Advances in Behavioral Pharmacology (Vol 1, pp. 167-227). New York: Acedemic Press.

Dinsmoor, J. A., Lee, D. M., \& Brown, M. M. (1986). Escape from serial stimuli leading to food. Journal of the Experimental Analysis of Behavior, 46, 259-279.

Dinsmoor, J. A. (1995) Tutorial. Stimulus Control: Part I. The Behavior Analyst, 18, 51-68.

Doweiko, H. E. (1990). Concepts of Chemical Dependency. Pacific Grove: Brooks/Cole.

Farmer, J. \& Schoenfeld, W. N. (1966). Varying temporal placement of an added stimulus in a fixed-interval schedule. Journal of the Experimental Analysis of Behavior, 9, 369-375.

Ferster, C.B. \& Skinner, B.F. (1957). Schedules of reinforcement. AppletonCentury-Crofts, New York.

Fry, W., Kelleher, R.T., \& Cook, L. (1960). A mathematical index of performance on fixed-interval schedules of reinforcement. Journal of the Experimental Analysis of Behavior, 3, 193-199.

Geyer, M. A., Russo, P. V., Segal, D. S., \& Kuczenski, R. (1982). Effects of apomorphine and amphetamine on patterns of locomotor and investigatory behavior in rats. Pharmacology, Biochemistry, and Behaivor, 28, 393-399.

Goodman, L. S. \& Gilman, A. (1996). The Pharmacological Basis of Therapeutics. New York: McGraw-Hill. 
Harris, R. A., Snell, D. \& Loh, H. H. (1978a). Effects of stimulants, anorectics, and related drugs on schedule-controlled behavior. Psychopharmacology, 56, 49-55.

Heifetz, S. A. \& McMillan, D. E. (1971). Development of behavioral tolerance to morphine methadone using the schedule-controlled behavior of the pigeon.

Psychopharmacologia, 19, 40-52.

Hendry, D. P. \& Dillow, P. V. (1966). Observing behavior during interval schedules. Journal of the Experimental Analysis of Behavior, 9, 337-349.

Hendricks, J. (1966). Flicker thresholds as determined by a modified conditioned suppression procedure. Journal of the Experimental Analysis of Behavior, 9, 501-506.

Julian, R. M. (1998). A Primer of Drug Action. New York: W.H. Freeman and Company.

Katz, J. L. (1982). Rate-dependent effects of d- and 1-amphetamine on schedulecontrolled responding in pigeons and squirrel monkeys. Neuropharmacology, 21, 235242.

Katz, J. L., \& Goldberg, S. R. (1986). Effects of ethylketazocine and morphine on schedule-controlled behavior in pigeons and squirrel monkeys. Journal of Pharmacology and Experimental Therapeutics, 239, 433-441.

Kelleher, R. T. \& Morse, W. H. (1968). Determinants of the specificity of the behavioral effects of drugs. Ergebnisse der Physiologie Biologischen Chemie und Experimentallen Pharmakologie, 60, 1-56.

Kendall, S.B. (1972). Some effects of response-dependent clock stimuli in a fixed-interval schedule. Journal of the Experimental Analysis of Behavior, 17, 161-168. 
Killeen, P.R. \& Fetterman, J.G. (1988). A behavioral theory of timing. Psychological Review, 95, 274-295.

Kraemer, P. J., Randall, C. K., Dose, J. M., \& Brown, R. W. (1997). Impact of d-amphetamine on temporal estimation in pigeons tested with a production procedure. Pharmacology, Biochemistry, and Behavior, 58, 323-327.

Laties, V.G. \& Weiss, B. (1966). Influence of drugs on behavior controlled by internal and external stimuli. Journal of Pharmacology and Experimental Therapeutics, $152,388-396$.

Leander, J. D. \& McMillan, D. E. (1974). Rate-dependent effects of drugs. I. Comparisons of d-amphetamine, pentobarbital and chlorpromazine on multiple and mixed schedules. Journal of Pharmacology and Experimental Therapuetics, 188, 726739.

McAuley, F. \& Leslie, J. C. (1986). Molecular analyses of the effects of damphetamine on fixed-interval schedule performance of rats. Journal of the Experimental Analysis of Behavior, 45, 207-219.

McKearney, J. W. (1974). Effects of d-amphetamine, morphine, and chlorpromazine on responding under fixed-interval schedules of food presentation or electric shock presentation. Journal of Pharmacology and Experimental Therapeutics, 190, 141-153.

McKearney, J. W. (1981). Rate dependency: Scope and limitations in the explanation and analysis of the behavioral effects of drugs. Advances in Behavioral Pharmacology, Vol. 3. 
McMillan, D. E. (1969). Effects of d-amphetamine on performance under several parameters of multiple fixed-ratio, fixed-interval schedules. $\underline{\text { Journal of }}$ Pharmacology and Experimental Therapuetics, 167, 26-33.

McMillan, D. E. (1979). Effects of d-amphetamine and caffeine on schedulecontrolled and schedule-induced responding. Journal of the Experimental Analysis of Behavior, 32, 445-456.

McMillan, D. E. \& Healey, M. L. (1976). Some effects of d-amphetamine and pentobarbital on performance under a long fixed-interval schedule. Journal of the Experimental Analysis of Behavior, 25, 389-399.

MED Associates, Inc. \& Tatham, T.A. (1991). MED-PC Medstate Notation. East Fairfield, VT: MED Associates, Inc.

Odum, A.L., Haworth, S.C., \& Schaal, D.W. (1998). Food-deprivation level alters the effect of morphine on pigeon's key pecking. Journal of the Experimental Analysis of Behavior, 69, 295-310.

Odum, A.L. \& Schaal, D.W. (1999). The effects of morphine on clocked fixedinterval performance: Stimulus function or strength of stimulus control? Behavioural Pharmacology,10, 243-255.

Odum, A.L. \& Schaal, D.W. (2000). The effects of morphine on fixed-interval patterning and temporal discrimination. Journal of the Experimental Analysis of Behavior, 74, 229-243.

Palya, W. L. \& Bevins, R. A. (1990). Serial conditioning as a function of stimulus, response, and temporal dependencies. Journal of the Experimental Analysis of Behavior, 53, 65-85. 
Richards, R. W. \& Rilling, M. (1972). Aversive aspects of a fixed-interval schedule of food reinforcement. Journal of the Experimental Analysis of Behavior, 17, 405-411.

Rhodus, D. M., Elsmore, T. F., \& Manning, F. J. (1974). Morphine and heroin effects on multiple fixed-interval schedule performance in rats. Psychopharmacologia, $\underline{40,} 147-155$.

Robbins, T.W., (1981). Behavioral determinants of drug action: Ratedependency revisisted. In S.J. Cooper (Ed.) Theory in Psychopharmacology, (Volume 1). New York: Academic Press, 1-63.

Sanger, D. J. \& Blackman, D. E. (1974). Rate-dependent effects of drugs: Review of the literature. Pharmacology, Biochemistry, and Behavior, 4, 73-83.

Schaal, D. W., Miller, M. A., \& Odum, A. L. (1995). Cocaine's effects on foodreinforced pecking in pigeons depend on food-deprivation level. $\underline{\text { Journal of the }}$ Experimental Analysis of Behavior, 64, 61-73.

Schneider, B. A. (1969). A two-state analysis of fixed-interval responding in the pigeon. Journal of the Experimental Analysis of Behavior, 12, 677-687.

Segal, E.F. (1962). Exteroceptive control of fixed-interval responding. Journal of the Experimental Analysis of Behavior, 5, 49-57.

Spetch, M. L. \& Treit, D. (1984). The effect of d-amphetamine on short-term memory for time in pigeons. Pharmacology, Biochemistry, and Behavior, 21, 663-666.

Thompson, T. (1984). Behavioral Mechanisms of Drug Dependence. In Thompson, T., Dews, P.B, \& Barrett, J. E. (Eds.) Advances in Behavioral Pharmacology, Vol 4. (pp. 1-45). Orlando: Academic Press. 
Thompson, T. \& Schuster, C.R. (1968). Behavioral Pharmacology. Engelwood Cliffs, NJ: Prentice-Hall.

Vaillant, G. E. (1967). A comparison of antagonists of physotigmine-induced suppression of behavior. Journal of Pharmacology and Experimental Therapuetics, 157, 636-648.

van Haaren, F. (1993). Schedule-controlled behavior: Positive reinforcement. In J. P. Huston (Series Ed.) and F. van Haaren (Vol. Ed.), Methods in behavioral pharmacology: Vol. 10, Techniques in the behavioral and neural sciences (pp. 81-99). Amsterdam: Elsevier. 